Res Pública Revista de Historia de las Ideas Políticas

ISSN: $1131-558 \mathrm{X}$

http://dx.doi.org/10.5209/rpub.68390

\title{
La representación en debate. Una lectura sobre la crítica benjaminiana al pensamiento de Carl Schmitt*
}

\author{
Guillermo Bialakowsky**
}

Recibido: 16 de marzo de 2019 / Aceptado: 25 noviembre de 2019

Resumen. El presente artículo se propone examinar el debate que Walter Benjamin establece con Carl Schmitt al interior de las Tesis "Über den Begriff der Geschichte" ("Sobre el concepto de historia"). Se buscará sostener que el problema de la representación constituye la clave hermenéutica para comprender el vínculo entre la reformulación benjaminiana de las nociones de tiempo e historia y su crítica a las ideas de Schmitt. Partiendo de la disputa en torno a la célebre noción de "estado de excepción" (Ausnahmezustand), se rastrearán los elementos que puedan dilucidar el alcance de dicha crítica. Finalmente, se analizarán las implicancias que se desprenden de la disputa desarrollada.

Palabras clave: W. Benjamin; C. Schmitt; representación; soberanía; estado de excepción.

\section{[en] The Representation in Debate. A Reading of the Benjaminian Critique of Carl Schmitt's Thought}

\begin{abstract}
This article aims to examine the discussion that Walter Benjamin establishes with Carl Schmitt within the Theses "Über den Begriff der Geschichte" ("On the concept of history"). I will argue that the problem of representation is the hermeneutical key to understand the link between Benjamin's reformulation of the notions of time and history and his critique of Schmitt's ideas. Starting from the dispute about the famous notion of "state of exception" (Ausnahmezustand), the paper will trace the elements that can elucidate the scope of this critique. Finally, the conclusions will analyze the implications that arise from the dispute.
\end{abstract}

Keywords: W. Benjamin; C. Schmitt; Representation; Sovereignty; State of Exception.

Sumario. 1. La soberanía: entre el estado de excepción y el problema de la representación. 2. El soberano representa la historia: hacia una crítica del tiempo y de la historia. 3. Memoria e imagen dialéctica: hacia nuevas categorías de tiempo y de historia. 4. Consideraciones finales. 5 Bibliografía.

Cómo citar: Bialakowsky, G. (2020). La representación en debate. Una lectura sobre la crítica benjaminiana al pensamiento de Carl Schmitt. Res Pública. Revista de Historia de las Ideas Politicas, 23(1), 21-35.

La crítica que Walter Benjamin ha elaborado hacia el pensamiento de Carl Schmitt se encuentra fuertemente presente en la filosofía contemporánea. Sin embargo, un cuidadoso análisis respecto de esta cuestión al interior de las Tesis "Sobre el concepto de historia" ("Über den Begriff der Geschichte") encierra diversas dificultades interpretativas. Por un lado, una gran parte de la disputa se encuentra implícita y fragmentada a lo largo de sus obras. Por el otro, la especificidad del abordaje de estos pensadores implica una reflexión que va de la teología a la estética, de la filosofía política a la filosofía de la historia. Nuestro trabajo buscará mostrar la relevancia de una temática que ha sido relegada significativamente en la interpretación de las Tesis. En otras palabras, consideramos que el problema de la repre- sentación posee una particular potencialidad hermenéutica como hilo conductor para repensar la apropiación crítica que Benjamin realiza del pensamiento schmittiano.

En el primer apartado, analizaremos el modo en el que esta lectura se inscribe en el texto partiendo de la exégesis de la Tesis VIII, considerada el punto nodal por su referencia a la noción schmittiana de "estado de excepción" (Ausnahmezustand). No obstante, para comprender la lectura de Benjamin, no sólo resulta crucial atender al vínculo establecido con la obra de Schmitt sino también comprender la inversión conceptual elaborada por el filósofo berlinés. Por lo tanto, su pensamiento requiere que abordemos las constelaciones trazadas tanto entre sus categorías como entre sus escritos. Si bien puede afirmarse que ambos autores

\footnotetext{
El presente artículo ha sido posible en el marco de mi Beca Interna Doctoral del Consejo Nacional de Investigaciones Científicas y Técnicas de la Argentina (CONICET) para el desarrollo de mi Tesis doctoral en cotutela entre la Universidad de Buenos Aires y l'Université Paris 8 VincennesSaint-Denis. Agradezco por su ayuda invaluable a mis directores Dra. Mónica B. Cragnolini y Dr. Patrice Vermeren.

** Universidad de Buenos Aires, Argentina

guillebiala@gmail.com
} 
parten de un rechazo de la representación liberal y un acercamiento a las temáticas teológicas, para el filósofo berlinés se tratará de poner en cuestión el nexo mítico que el Derecho establece con la violencia (Gewalt). Por el contrario, Schmitt se propondrá recuperar una categoría eminente de representación que sea capaz de sostener el Estado como unidad política duradera.

Ahora bien, en el segundo apartado, el desarrollo de nuestra hipótesis nos conduce hacia el análisis de la dimensión histórico-temporal del problema de la representación. Desde nuestro punto de vista, los desarrollos benjaminianos apuntan a desmontar la concepción tradicional del tiempo y de la historia que se corresponden a la estructura del pensamiento político schmittiano. Investigaremos, desde esta perspectiva, la especificidad de la lectura que realiza Benjamin de las categorías schmittianas. En otros términos, si la noción de tiempo homogéneo y re-presentable se encuentra a la base del "estado de excepción" schmittiano, Benjamin se pregunta por las herramientas metodológicas que permitan su integral reformulación. Si bien puede afirmarse que esta búsqueda en pos de un nuevo método y una nueva teoría del conocimiento llega a su expresión filosófica más contundente en las Tesis, resulta insoslayable atender a textos fundamentales para su elaboración: desde Ursprung des deutschen Trauerspiels (El origen del drama barroco alemán, redactado en 1925 y publicado en 1928) hasta el inconcluso Passagen-Werk (Obra de los Pasajes).

A partir de este análisis, en el tercer apartado nos detendremos a considerar el despliegue de la propuesta benjaminiana. Analizaremos el modo en el que Benjamin busca reconstruir la experiencia histórico-política desde la categoría de dialektisches Bild (imagen dialéctica) como respuesta frente a la representación tradicional. La "tradición de los oprimidos" exige una filosofía política de la historia que se corresponda con una crítica radical del tiempo histórico. En tal sentido, indagaremos en el alcance de nociones como Jetztzeit (tiempo-ahora) y Eingedenken (recordación, rememoración), las cuales se han constituido en condiciones de posibilidad para comprender su apuesta filosófica.

Finalmente, en las consideraciones finales, ponderaremos la pertinencia de la hipótesis que ha enhebrado al trabajo. ¿Cuáles son los desplazamientos específicos que Benjamin realiza en su crítica a Schmitt en torno al problema de la representación? ¿Qué implicancias tiene, en este contexto, la reformulación del tiempo y la historia? Y por último: ¿en qué sentido la filosofía política de la historia que nos propone Benjamin puede considerarse una crítica radical del pensamiento schmittiano?

\section{La soberanía: entre el estado de excepción y el problema de la representación}

$\mathrm{Al}$ inicio de la Tesis VIII, Benjamin afirma: "La tradición de los oprimidos nos enseña que el «estado de excepción» [der «Ausnahmezustand»] en el que vivimos es la regla. Debemos llegar a un concepto de historia que se corres- ponda con esta situación"'. En apenas unas líneas el autor condensa la inversión que se propone realizar sobre el pensamiento schmittiano. Benjamin construye aquí una clara referencia, subrayada por el uso de las comillas, a la metodología ya presente en Die Diktatur (1921), pero que encuentra su expresión más célebre en el pasaje que abre el capítulo I de Politische Theologie. Vier Kapitel zur Lehre von der Souveränität (Teología política. Cuatro capitulos sobre la doctrina de la soberanía, de 1922): "Soberano es quien decide sobre el estado de excepción"2.

Ahora bien, ¿en qué consiste el desplazamiento propuesto por Benjamin? Schmitt expone en dicho texto una noción de soberanía basada en el caso más extremo. Cabe destacar que el Jurist no piensa aquí en cualquier medida de policía o de necesidad, sino en la suspensión ilimitada del Derecho, en la cual la decisión soberana más eminente busca salvaguardar la existencia misma del Estado. Se trata de una decisión absoluta que se ha liberado de toda traba normativa. Aun cuando no pueda considerarse un orden jurídico stricto sensu, el autor considera que dicho estado excepcional se distingue efectivamente de la anarquía o del caos ya que subsiste todavía un orden. Schmitt aborda la paradoja de este modo:

La existencia del Estado deja en este punto acreditada su superioridad sobre la validez de la norma jurídica (...) Los dos elementos que integran el concepto del orden jurídico se enfrentan uno con otro y ponen de manifiesto su independencia conceptual. Si en los casos normales cabe reducir al mínimo el elemento autónomo de la decisión, es la norma la que en el caso excepcional se aniquila. Sin embargo, el caso excepcional sigue siendo accesible al conocimiento jurídico, porque ambos elementos -la norma y la decisión- permanecen dentro del marco de lo jurídico ${ }^{3}$.

Schmitt destaca esta perspectiva que implica comprender la norma mediante lo excepcional estableciendo un vínculo con Søren Kierkegaard. Aunque el jurista alemán aluda veladamente al pensador danés como un "teólogo protestante" del siglo XIX, la referencia corresponde a su

W. Benjamin, "Sobre el concepto de historia" y "Materiales preparatorios del escrito", en R. Mate, Medianoche en la historia, (trad. R. Mate), Madrid, Trotta, 2006, p. 143. Si bien la edición de Reyes Mate cuenta con una versión trilingüe de las Tesis, cabe señalar que éstas pueden encontrarse en las Gesammelte Schriften en: W. Benjamin, Gesammelte Schriften I/I, R. Tiedemann y H. Schweppenhäuser (eds.), con la colaboración de Th. W. Adorno y G. Scholem, Frankfurt a.M., Suhrkamp, 1991, pp. 691-704.

C. Schmitt, Teología política. Cuatro capitulos sobre la doctrina de la soberanía, en Teología política, trad. F. J. Conde y J. Navarro Pérez, epílogo de J. L. Villacañas, Madrid, Trotta, 2009, p. 13.

C. Schmitt, Teología política, op. cit., p. 17-18. Carlo Galli afirma sobre esta cuestión: "En cuanto mantiene unidas (sin síntesis) tanto la excepción como la forma jurídica, la soberanía decidiente de la cual Schmitt ha hablado en los dos primeros capítulos [de Politische Theologie] si no es, entonces, «necesaria» (no hay de hecho «necesidad» en la modernidad, sino sólo contingencia) es, ciertamente, «indispensable» en una dimensión epocal que hace de lo Moderno la época de la excepción. Sólo la soberanía decisionista y representativa es adecuada para habitar políticamente la modernidad, para evocar continuamente la desmesurada energía necesaria para que se dé el orden, para combatir toda desviación hacia una concepción «automática» de la política" (C. Galli, Lo sguardo di Giano. Saggi su Carl Schmitt, Bologna, il Mulino, 2008, p. 81). 
ensayo de 1843 La repetición ${ }^{4}$. Frente a las teorías del Estado positivista y normativista, que buscan excluir todo fenómeno excepcional del ámbito del Derecho, Schmitt afirma una metodología basada en la excepción. El autor sostiene: "La excepción es más interesante que el caso normal. Lo normal nada prueba; la excepción, todo; no sólo confirma la regla, sino que ésta vive de aquélla. En la excepción, la fuerza de la vida efectiva hace saltar la costra de una mecánica anquilosada en repetición"5. Según Samuel Weber, esta inclinación a reflexionar sobre el caso excepcional es uno de los puntos más relevantes para subrayar en el vínculo con Benjamin 6 . Sin embargo, como veremos luego, sostendremos que Benjamin se propone una reformulación integral de dicha concepción. Por lo pronto, puede servirnos como indicio la Tesis VIII: resulta claro que Benjamin busca allí poner en evidencia que la excepción es lo nor-

Cf. C. Schmitt, Teología política, op cit. p. 20; S. Kierkegaard, La repetición, trad. D. Gutiérrez Rivero, Madrid, Alianza, 2009. En relación a la presencia de Kierkegaard en el pensamiento de Schmitt, cf. B. Conrad, "Kierkegaard's Moment. Carl Schmitt and His Rhetorical Concept of Decision", en K. Palonen (ed.), Redescriptions: Yearbook of Political Thought, Conceptual History and Feminist Theory, Berlin, Lit Verlag, 2011, pp. 145-171; J. Dotti, "Ménage à trois sobre la decisión excepcional. Kierkegaard, Constant y Schmitt", en Deus Mortalis. Cuaderno de filosofia política 4, 2005, pp. 303-380.

C. Schmitt, Teología política, op. cit., p. 19. Autores como Carlo Galli, Reinhard Mehring y William Scheuerman han subrayado el modo en el que Schmitt realiza su primera aproximación a la noción de Ausnahmezustand durante la Primera Guerra Mundial. En este sentido, el análisis schmittiano se inicia a partir de la publicación de dos ensayos sobre el estado de sitio (Belagerungzustand) en la revista Zeitschrift fur das gesamte Strafrechtswissenschaft (cf. C. Schmitt "Diktatur und Belagerungszustand", en Zeitschrift fur das gesamte Strafrechtswissenschaft 38, 1916, pp. 138-162; C. Schmitt, "Die Einwirkungen des Kriegszustandes auf das ordentliche strafprozessuale Verfahren", en Zeitschrift fur die gesamte Strafrechtswissenschaft 38, 1917, pp. 783-797; C. Galli, Genealogia della politica, Bologna, Il Mulino, 1996, pp. 422-423; R. Mehring, Carl Schmitt: Aufstieg und Fall. Eine Biographie, München, C.H. Beck, 2009; R. Mehring, Kriegstechniker des Begriffs. Biographische Studien zu Carl Schmitt, Tübingen, Mohr Siebeck, 2014; R. Mehring, Carl Schmitt: Denker im Widerstreit: Werk - Wirkung - Aktualität, Freiburg/München, Verlag Karl Alber, 2017; W. Scheuerman, Carl Schmitt: The End of Law, Lanham, Rowman \& Littlefield, 1999; W. Scheuerman, "States of Emergency", en J. Meierhenrich y O. Simons (eds.), The Oxford Handbook of Carl Schmitt, Oxford, Oxford University Press, 2016, pp. 547-569). En relación con la vasta bibliografía sobre las categorías de Ausnahmezustand, Ernstfall y Notfall, cf. sobre todo A. Peisl y A. Mohler (eds.), Der Ernstfall (Schriften der "Carl Friedrich von Siemens-Stiftung” Bd. 2), Frankfurt a.M./ Berlin/Wien, Propyläen Verlag, 1979; G. Gómez Orfanel, Excepción y normalidad en el pensamiento de Carl Schmitt, Madrid, Centro de Estudios Constitucionales, 1986, pp. 37-88; M. Schmitz, Die Freund-Feind-Theorie Carl Schmitts. Entwurf und Entfaltung, KölnOpladen, Westdeutscher Verlag, 1965, p. 118 ss; G. Schwab, The Challenge of the Exception: An Introduction to the Political Ideas of Carl Schmitt between 1921 and 1936, 2da ed., New York, Greenwood, 1989; H. Hofmann, Legitimität gegen Legalität. Der Weg der politischen Philosophie Carl Schmitts, 2da ed., Berlin, Duncker \& Humblot, 1992, p. 62 ss; J. Dotti, "Teología política y excepción”, en Daimon. Revista de Filosofia 13, 1996, pp. 129-140; D. Dyzenhaus, "Introduction: Carl Schmitt", en D. Dyzenhaus (ed.), Law as Politics: Carl Schmitt's Critique of Liberalism, Durham, Duke University Press, 1998, pp. 1-20; W. Scheuerman, Carl Schmitt: The End of Law, Boston, Rowman \& Littlefield, 1999; G. Agamben, Stato di eccezione. Homo sacer, II, 1, Torino, Bollati Boringhieri, 2003; J. Ferejohn y P. Pasquino, "The Law of the Exception: A Typology of Emergency Powers", en International Journal of Constitutional Law 2, 2004, pp. 210-239.

6 Cf. S. Weber, "Taking Exception to Decision: Walter Benjamin and Carl Schmitt", en Diacritics: a review of contemporary criticism 22.3/4, 1992, pp. 5-18, aquí p. 6 . mal. El desarrollo de este trabajo nos permitirá vislumbrar por qué Benjamin considera que la fuerza conceptual necesaria para realizar este desplazamiento se encuentra en una crítica de la representación y una reformulación de los conceptos de tiempo e historia. En este sentido afirmamos que las diferencias que Benjamin ya había marcado con el pensamiento de Schmitt hasta ese momento adquieren en las Tesis su mayor intensidad y radicalidad. En el contexto de una serie de acontecimientos históricos que han sacudido a Europa (el hundimiento de la República de Weimar, la consolidación del nazismo y el Pacto Ribbentrop-Mólotov, si nombramos algunos de los más resonantes), Benjamin se encuentra elaborando una nueva teoría del conocimiento y una nueva metodología que permiten que la discusión con Schmitt alcance su máximo potencial filosófico. En tal sentido, la Tesis VIII reafirma la inversión conceptual: "Nuestra tarea histórica consistirá entonces en suscitar la venida del verdadero estado de excepción, mejorando así nuestra posición en la lucha contra el fascismo"7.

Ahora bien, ¿en qué consiste el wirkliche Ausnahmezustand ("wirkliche" podría traducirse tanto por "verdadero" como por "efectivo") que plantea Benjamin? Para comprender el alcance de esta inversión, resultará ineludible estudiar el modo en el que se ligan en el texto una recuperación del mesianismo judío y su categoría de redención (Erlösung) con una lectura heterodoxa del marxismo y su noción de revolución. Esto se encuentra planteado desde la primera Tesis en la que el autómata -el materialismo histórico- esconde a la enana fea de la teología (pues sólo tomándola a su servicio será capaz de ganar cualquier partida). La Tesis VIII concluye:

El que sus adversarios se enfrenten a él [al fascismo] en nombre del progreso, tomado éste por ley histórica, no es precisamente la menor de las fortunas del fascismo. No tiene nada de filosófico [kein philosophisches] asombrarse de que las cosas que estamos viviendo sean "todavía" posibles en pleno siglo XX. Es un asombro que no nace de un conocimiento, conocimiento que de serlo tendría que ser éste: la idea de historia que provoca ese asombro no se sostiene ${ }^{8}$.

Tomando en consideración estas líneas, resulta crucial evitar una interpretación de las categorías de redención y revolución como punto final de una teleología. En tal sentido, se trata de poner en cuestión una concepción de la historia que se asume dirigida en línea recta hacia el fin a través de leyes inmutables. Stéphane Mosès ha subrayado la ruptura de la temporalidad histórica en la que consiste la noción benjaminiana de redención. En L'Ange de l'histoire (El ángel de la historia), afirma: "Ésta no se sitúa en algún punto en el fin de los tiempos; todo lo contrario, acontece (o puede acontecer) en cada instante, en la exacta medida en que cada instante del tiempo -captado en su singularidad absoluta- hace aparecer un nuevo estado del mundo". Como veremos luego en profundidad, la crítica al concepto de progreso comporta una crítica política al concepto de tiempo

W. Benjamin, "Sobre el concepto de historia", op. cit., p. 143.

Ibidem.

S. Mosès, El ángel de la historia. Rosenzweig, Benjamin, Scholem, trad. A. Martorell, Madrid, Cátedra, 1997, p. 131. 
homogéneo y vacío ${ }^{10}$. La elaboración de Benjamin no se propone permanecer en su pars destruens.

En tal sentido, ya en su artículo de 1921 "Zur Kritik der Gewalt" ("Para una crítica de la violencia") el autor había insistido en que la perspectiva cronológica no tiene nada de filosófico: "La crítica de la violencia es la filosofía de su propia historia. Es «filosofía» de dicha historia porque ya la idea que constituye su punto de partida hace posible una postura crítica, diferenciadora y decisiva respecto a sus datos cronológicos"11. Este texto posee además una particular importancia para poder dilucidar el abordaje benjaminiano sobre las categorías de Estado y Derecho ${ }^{12}$. Resulta sugerente la hipótesis de Giorgio Agamben que sostiene que es "Para una crítica de la violencia" el primer disparador del diálogo conceptual entre Benjamin y Schmitt ${ }^{13}$. Según esta interpretación, resulta plausible que Schmitt haya leído el escrito en su publicación original en el Archiv für Sozialwissenschaften und Sozialpolitik. De esta manera, Politische Theologie (1922) ya sería una respuesta a las intuiciones volcadas por Benjamin en el ensayo del año anterior. Si el filósofo berlinés había postulado una violencia más allá de todo Derecho, Schmitt se propone subsumir la decisión soberana que suspende la ley al orden e incluso al ámbito

10 Cf. Tesis XIII (W. Benjamin, "Sobre el concepto de historia", op. cit., pp. 211-212).

11 W. Benjamin, Para una crítica de la violencia y otros ensayos, trad. R. Blatt, Madrid, Taurus, 2001, p. 41.

12 Asimismo, la relevancia de este texto para la posterior discusión filosófica contemporánea ha sido insoslayable. Alfonso Galindo Hervás ha condensado dicha herencia del siguiente modo: "Existe una rica tradición de pensamiento que halla su fuente en el judaísmo que destila el escrito de Walter Benjamin sobre la violencia: Zur Kritik der Gewalt. La prohibición de toda imagen, de todo nombre, que ose capturar el exceso, lo divino, se troca en ese breve pero intenso texto en establecimiento de un jorismós insuperable entre la acción humana y la trascendencia. Un abismo que justifica la condena ab integro de la esfera jurídica en su ingenuo pulso por obrar la justicia - un abismo que motiva el adjetivo «impolítico». Muy al contrario, para Benjamin el derecho es la violencia, pura inmediatez, fuerza. Y tiene como toda legitimidad y origen la de la decisión. No existe fruto bondadoso alguno que lo redima. Tampoco cabe oponerle un contrapeso del mismo género, otro derecho" (A. Galindo Hervás, "Lo impolítico, la esquizofrenia. Variaciones sobre el mito", en ALFA 14, 2004, pp. 103-111, Versión electrónica en http:/www.saavedrafajardo.org/archivos/trabajos/trab003-agh.pdf, consultado el 10/01/2017, pp. 1-9, aquí p. 2). Para una profundización de este vínculo crítico entre teología política y pensamiento impolítico, cf. del mismo autor A. Galindo Hervás, La soberanía. De la teología política al comunitarismo impolítico, Murcia, Res Publica, 2003; A. Galindo Hervás, “Mesianismo impolítico", en Isegoría 39, 2008, pp. 239-250; y A. Galindo Hervás, Pensamiento impolítico contemporáneo. Ontología (y) politica en Agamben, Badiou, Esposito y Nancy, Madrid, Sequitur, 2015.

13 Cabe destacar en este sentido la interpretación propuesta por Agamben de una "gigantomaquia en torno a un vacío" (cf. G. Agamben, Stato di eccezione, op. cit., 2003, pp. 68-83). A partir de la exégesis de los textos en diálogo entre Benjamin y Schmitt, el autor también subraya, como veremos luego en nuestro desarrollo, la imposibilidad de acotar espacio-temporalmente el estado de excepción. Para un análisis pormenorizado sobre la posición agambeniana, en el que no podemos profundizar aquí, cf. P. Damai, "The Killing Machine of Exception: Sovereignty, Law, and Play in Agamben's State of Exception", en CR: The New Centennial Review 5.3, 2005, pp. 255276; D. Pan, "Against Biopolitics: Walter Benjamin, Carl Schmitt, and Giorgio Agamben on Political Sovereignty and Symbolic Order", en The German Quarterly 82.1, 2009, pp. 42-62; P. Fleisner, La vida que viene, Buenos Aires, EUDEBA, 2015. Con respecto a las lecturas encontradas en torno a Georges Sorel, cf. J-W. Müller, "Myth, law and order: Schmitt and Benjamin read reflections on violence", en History of European Ideas 29, 2003, pp. 459-473. de lo jurídico. Sin embargo, la inversión de la Tesis VIII, según Agamben, pondría en evidencia la posición política reaccionaria que implica la paradoja schmittiana. El pensador italiano concluye el giro argumentativo resaltando que, a diferencia de Schmitt, la crítica a la representación liberal comporta para Benjamin poner en cuestión toda legalidad, toda mediación que apunte a recubrir la violencia soberana que le es propia. No obstante, cabe señalar que Agamben no se pregunta allí por el vínculo explícito que Benjamin establecía en "Para una crítica de la violencia" con la crítica a la perspectiva cronológica ya citada. El filósofo berlinés sostiene:

Una visión que se reduzca a considerar lo más inmediato, a lo sumo intuirá el ir y venir dialéctico de la violencia en forma de violencia fundadora de derecho o conservadora de derecho. Esta ley de oscilación se basa en que, a la larga, toda violencia conservadora de derecho indirectamente debilita a la fundadora de derecho en ella misma representada, al reprimir violencias opuestas hostiles ${ }^{14}$.

¿Cómo puede entenderse este encadenamiento conceptual? Para responder a este interrogante, el cual nos conduce hacia la problemática del tiempo y de la historia, tendremos que ahondar en el recorrido filosófico realizado por el autor. Entre los puntos en común que se suelen subrayar en la bibliografía sobre el debate entre Benjamin y Schmitt, la crítica a la noción de representación propia del parlamentarismo ha sido una de las más comentadas y trabajadas ${ }^{15}$. En "Para una crítica de la violencia", Benjamin se propone desplazar la dicotomía entre medios y fines que supondrían tanto el Derecho positivo como el Derecho natural. La violencia es entendida por ambos en el plano de los medios. Por un lado, el iusnaturalismo asumirá que los medios son justos en el caso de que los fines así lo sean. Por el otro, el Derecho positivo considera que los medios legítimos implican que los fines serán justos. Para Benjamin, estas conceptualizaciones no hacen más que encerrar la violencia en una circularidad infernal entre aquella violencia que funda Derecho y aquella que lo conserva. Sin embargo, la interrupción de este ciclo resultaría posible a través de una "violencia divina" (göttliche Gewalt) ${ }^{16}$. Mientras el dispositivo de la representación propio del parlamentarismo intenta velar el vínculo indisociable entre Derecho y violencia, la violencia divina consistiría en la irrupción de una pura (reine) e inmediata fuerza de aquello que es irrepresentable. Esa otredad radicalmente heterogénea sería la única capaz de paralizar la violencia mítica y suspender una refundación del Derecho.

En este sentido, no cabe duda que "Para una crítica de la violencia" resulta fundamental para la discusión con Schmitt, sobre todo teniendo en cuenta que su lectura sobre la

W. Benjamin, Para una critica de la violencia y otros ensayos, op. cit., p. 44.

15 Cf. S. Weber, op. cit., p. 6; J. L. Villacañas, y R. García, "Walter Benjamin y Carl Schmitt: Soberanía y estado de excepción", en Daimon. Revista de filosofía 13, 1996, pp. 41-60; H. Bredekamp, "From Walter Benjamin to Carl Schmitt, via Thomas Hobbes", en Critical Inquiry, 25.2, trad. M. Thorson Hause y J. Bond, 1999, pp. 247-266; H. Bredekamp, "Walter Benjamin's Esteem for Carl Schmitt”, en J. Meierhenrich y O. Simons (eds.), op. cit., pp. 679-704.

16 Cf. W. Benjamin, Para una crítica de la violencia y otros ensayos, op. cit., p. 41. 
representación también se entrelaza con la pregunta por la relación entre política y trascendencia. No puede reducirse, en este sentido, el alcance que posee la religión tanto para el pensamiento de Schmitt como para el de Benjamin. El análisis del problema de la representación muestra en qué medida para Schmitt resulta fundamental repensar el fenómeno de la secularización. De modo análogo, también podemos resaltar el lugar que ocupa para Benjamin (tal como podemos observarlo por ejemplo en la Tesis XVIIa). De esta manera, puede comprenderse por qué el tercer capítulo de Teología política comienza con estas célebres líneas:

Todos los conceptos centrales de la moderna teoría del Estado son conceptos teológicos secularizados. Lo cual es cierto no sólo por razón de su evolución histórica, en cuanto fueron transferidos de la teología a la teoría del Estado, convirtiéndose, por ejemplo, el Dios omnipotente en el legislador todopoderoso, sino también por razón de su estructura sistemática, cuyo conocimiento es imprescindible para la consideración sociológica de estos conceptos. El estado de excepción tiene en la jurisprudencia análoga significación que el milagro en la teología. Sólo teniendo conciencia de esa analogía se llega a conocer la evolución de las ideas filosófico-políticas en los últimos siglos. Porque la idea del moderno Estado de derecho se afirmó a la par que el deísmo, con una teología y una metafísica que destierran del mundo el milagro y no admiten la violación con carácter excepcional de las leyes naturales implícita en el concepto del milagro y producido por la intervención directa, como tampoco admiten la intervención directa del soberano en el orden jurídico vigente. El racionalismo de la época de la Ilustración no admite el caso excepcional en ninguna de sus formas. Por eso la convicción teísta de los escritores conservadores de la contrarrevolución pudo hacer el ensayo de fortalecer ideológicamente la soberanía personal del monarca con analogías sacadas de la teología teísta ${ }^{17}$.

Como afirma el estudioso italiano Carlo Galli, no se trata para Schmitt de negar las transformaciones que constituyen la modernidad, sino de refutar la autointerpretación que la filosofía moderna ha hecho de sí misma como corte absoluto con la tradición ${ }^{18}$. Ello significa rechazar la lectura de la secularización como mero pasaje aséptico de categorías religiosas a conceptos científicos. La neutralización progresiva, llevada a su extremo por la perspectiva económico-liberal, busca ocultar la raíz y la estructura de aquello que hace posible la soberanía. Al considerar que la representación liberal privada y civil (Vertretung o Stellvertretung) no resulta verdaderamente capaz de sostener el orden político, Schmitt se propone recuperar una noción fuerte de representación (Repräsentation). Giuseppe Duso es uno de los teóricos que más profundamente ha investigado sobre la importancia de la noción de representación para comprender la lectura que Schmitt realiza sobre las categorías políticas centrales de la modernidad. Desde su perspectiva, la teología política schmittiana tendría su raíz conceptual en la representación de la "Idea"19. Esta cuestión es abor-

C. Schmitt, Teología política, op. cit., p. 37.

18 Cf. C. Galli, Lo sguardo di Giano, op. cit., p. 81.

19 Sobre esta cuestión, cf. G. Duso, "Carl Schmitt: teología política e lógica dei concetti politici moderni”, en Daimon. Revista de Filosofia 13, 1996, pp. 77-98; y G. Duso, La rappresentanza politica: genesi e crisi del concetto, Milano, Franco Angeli, 2003. dada por Schmitt en el pequeño libro que publica al año siguiente de Teología Politica: Römischer Katholizismus und politische Form (Catolicismo romano y forma politica de 1923). En oposición a la Vertretung, la cual supone una débil suma de intereses particulares, inmanentes y fragmentados, es necesario para el autor atender a la analogía estructural entre el Estado y la Iglesia como complexio oppositorum. La fuerza de esta institución se basa en la capacidad de representar aquello que trasciende toda suma de individuos y resulta estructuralmente invisible. Por tanto, el necesario "hacer visible" (sichtbar machen) sólo puede ser llevado a cabo, según Schmitt, por una autoridad personal. El jurista alemán desarrolla:

La Idea de la representación [Die Idee der Repräsentation] en cambio está tan dominada por el pensamiento de una autoridad personal que tanto el representante [Repräsentant] como el representado [Repräsentierte] deben afirmar una dignidad personal. No se trata de un concepto cosificado. Sólo una persona puede representar en sentido eminente [Repräsentieren in eminenten Sinne], y de hecho -a diferencia de la simple "representación" [Stellvertretung]- sólo una persona con autoridad o una idea que, una vez representada, asimismo se personifica $^{20}$.

Esta cuestión ya se encontraba de modo incipiente en el artículo que Schmitt publica en 1917 "Die Sichtbarkeit der Kirche. Eine scholastische Erwägung" ("La visibilidad de la Iglesia. Una reflexión escolástica”). El autor sostiene en dicho texto que la estructura jerárquica de la Iglesia es la única capaz de sostener el legado de Cristo al institucionalizar su trascendencia. Para Schmitt, a diferencia del individualismo de tradición protestante, la comunidad católica puede representar eso mismo que por definición la excede y la trasciende. Sin embargo, cabe destacar que Schmitt no se propone, a partir de estos desarrollos, un retorno a una filosofía política pre-moderna o alguna especie de teocracia (como tampoco Benjamin, por supuesto) ${ }^{21}$. Resulta imposible para Schmitt negar el vacío metafísico-político que la filosofía moderna ha planteado. En otras palabras, no hay una sustancia originaria que permita superar todo conflicto político. Si fuera así, su noción de decisión (Entscheidung) no tendría un carácter existencial y creador de forma, sino que equivaldría a una mera enunciación de verdad. La verdadera representación, según Schmitt, no puede deducirse de ningún principio absoluto, tampoco de una norma hipotética fundamental o Grundnorm. Si el soberano representa al pueblo (ontológicamente múltiple, heterogéneo e imperceptible), es porque su decisión debe dar forma a una unidad homogénea que no se encuentra dada previamente.

En conclusión, la crítica de Schmitt a la representación liberal no implica para el autor dejar de lado la categoría.

20 C. Schmitt, Römischer Katholizismus und politische Form, Stuttgart, Klett-Cotta, 1984, pp. 35-36.

21 En cuanto al rechazo benjaminiano de la teocracia como subordinación de la política a la teología, vale la pena considerar los fragmentos cercanos a la temática de "Para una crítica de la violencia". Más allá de la interesante discusión sobre la datación entre Adorno, Scholem y Tiedemann, subrayamos aquí la proximidad conceptual con los fragmentos "Mundo y tiempo" (Cf. W. Benjamin, "Welt und Zeit", fr. 73, en Gesammelte Schriften VI, op. cit., pp. 98-100) y "Fragmento teológico-político" (Cf. W. Benjamin, "Theologisch-politisches Fragment", en Gesammelte Schriften II/1, op. cit., pp. 203-204). 
Muy por el contrario, la noción de Repräsentation es la apuesta schmittiana por reconstruirla de forma eminente. Sólo a partir de una apelación a la trascendencia de la "Idea" (Idee) resultaría posible asegurar una unidad política duradera. Se trata para Schmitt de formular una reductio ad unum que suture de modo estrictamente vertical la crisis moderna y la ausencia de un fundamento sustancialista ya que: "Ningún sistema político puede sobrevivir [überdauern] ni siquiera una generación con la mera técnica de la afirmación del poder [bloßer Technik der Machtbehauptung]"22.

\section{El soberano representa la historia: hacia una crítica del tiempo y de la historia}

Ahora bien, ¿qué significa en este contexto una categoría histórico-temporal como lo es la duración? Como ya hemos vislumbrado en el primer apartado, en la Tesis VIII Benjamin subraya que toda posición política quedará trunca en cuanto no pueda elaborar una caracterización de la temporalidad histórica que se le corresponda. Esta tarea, a la que el pensador dedica los últimos años de su vida y que ha quedado plasmada en las Tesis, es un indicio para considerar por qué Benjamin puede considerarse cercano y, a la vez, un crítico radical del jurista de Plettenberg. O, en otros términos, por qué Benjamin considera que la estructura del pensamiento de Schmitt se corresponde con una concepción tradicional del tiempo y de la historia.

Sin embargo, antes de profundizar en esta cuestión, resulta insoslayable atender al elogioso mensaje que Benjamin le dirige a Schmitt el 9 de diciembre de 1930 con motivo del envío de su libro El origen del drama barroco alemán. Esta pequeña carta ha generado grandes polémicas, desde su exclusión en la primera recopilación de su correspondencia por parte de los editores Theodor W. Adorno y Gershom Scholem, hasta la insistencia sobre su relevancia por parte de Jacob Taubes. Como ha señalado Bredekamp en su reciente y rigurosa reconstrucción de las lecturas en torno al vínculo entre Benjamin y Schmitt "Walter Benjamin's Esteem for Carl Schmitt" (2016), la publicación del libro de Taubes Ad Carl Schmitt. Gegenstrebige Fügung (Ad Carl Schmitt. Armonía de opuestos, de 1987) fue un verdadero punto de inflexión ${ }^{23}$. En este sentido, como indica también Mehring en " "Geist ist das Vermögen, Diktatur auszuüben» Carl Schmitts Marginalien zu Walter Benjamin", la carta de Benjamin ha ocupado un lugar privilegiado tanto de la reflexión de Taubes como del debate posterior ${ }^{24}$. De hecho, Taubes la consideró una

22 C. Schmitt, Römischer Katholizismus und politische Form, op. cit., p. 28.

23 Cf. H. Bredekamp, "Walter Benjamin's Esteem for Carl Schmitt", op. cit., p. 682; J. Taubes, Ad Carl Schmitt. Gegenstrebige Fügung, Berlin, Merve, 1987. Cabe señalar que el primer texto que trabaja en profundidad sobre este debate es el artículo de M. Rumpf, "Radikale Theologie: Walter Benjamins Beziehung zu Carl Schmitt", en P. Gebhardt et al, Walter Benjamin - Zeitgenosse der Moderne, Kronberg, Scriptor, 1976, pp. 37-50.

24 Cf. R. Mehring, "«Geist ist das Vermögen, Diktatur auszuüben» Carl Schmitts Marginalien zu Walter Benjamin”, en D. Weidner y S. Weigel, Benjamin-Studien 2, Fink Wilhelm, 2011, pp. 239-256. Nueva edición en R. Mehring, Kriegstechniker des Begriffs. Biographische Studien zu Carl Schmitt, op. cit., pp. 137-152, aquí pp. 138-141. mina que podría destruir la representación de la historia intelectual sobre el período de Weimar ${ }^{25}$. En este sentido, Bredekamp realiza un exhaustivo estudio sobre el derrotero que ha tomado esta polémica ${ }^{26}$. Con ocasión de su publicación en los Gesammelte Schriften, Tiedemann, su editor consideró que era "denkwürdig" ("memorable", "notable", aunque quizás podríamos traducir literalmente como "digno de pensarse") ${ }^{27}$. En dicha carta, Benjamin le expresa su deuda a Schmitt con respecto a la teoría de la soberanía y a la metodología de investigación utilizada paradigmáticamente en Die Diktatur. Este segundo aspecto ya estaba presente en el curriculum de 1928 que Benjamin escribe sobre sí mismo. Se subraya allí la influencia de Schmitt en la búsqueda de expresar e integrar las tendencias religiosas, metafísicas, políticas y económicas para conocer una época $^{28}$. Benjamin encuentra en el pensador de Plettenberg la apuesta por una integración de fenómenos que atraviesa su obra. Siguiendo estas indicaciones del propio Benjamin, Weber ha rastreado estos puntos en común en un texto que se ha convertido en una referencia ineludible para el análisis de dicho vínculo ${ }^{29}$. El autor reafirma la relevancia del Trauerspiel-Buch para el desarrollo posterior del diálogo. En relación a este texto, Weber subraya la influencia de Schmitt en las nociones de lo único-extremo (EinmaligExtreme) y de origen (Ursprung). Sin embargo, como veremos a continuación, ni la carta ni el curriculum permiten soslayar la crítica a Schmitt que comienza a desprenderse del Trauerspiel-Buch. Cuando Benjamin introduce las

\footnotetext{
J. Taubes, Ad Carl Schmitt, op. cit., p. 27.
}

26 Siguiendo a Treml y a Sander (cabe señalar que este último tenía un fuerte vínculo con Schmitt y fue el primero en publicar la carta de Benjamin del 9/12/1930), Bredekamp subraya que las referencias en el Trauerspiel-Buch de Benjamin a Die Dikatur de Schmitt fueron eliminadas de la reimpresión en las Gesammelte Schriften. Cf. H.-D. Sander, Marxistische Ideologie und allgemeine Kunsttheorie, Tübingen, Mohr, 1975, p. 173; M. Treml, en H. Kopp-Oberstebrink, Th. Palzhoff y M. Treml (eds.), Jacob Taubes and Carl Schmitt: Briefwechsel mit Materialien, München, Fink, 2012, pp. 273-298; H. Bredekamp, "Walter Benjamin's Esteem for Carl Schmitt", op. cit., p. 696.

27 Cf. Tiedemann, en W. Benjamin, Gesammelte Schriften I/3, op. cit., p. 887.

28 Cf. W. Benjamin, Gesammelte Schriften VI, op. cit., p. 219.

29 Weber no sólo advierte sobre la crítica al parlamentarismo liberal que los aúna, sino que resalta el rol de la noción de excepción (cf. S. Weber, op. cit., p. 6 ss). Por su parte, Bredekamp considera que el punto de mayor coincidencia resulta la prioridad conceptual del instante (Augenblick) y una crítica al tiempo vacío de sentido que propone el cientificismo. También cabe destacar el interés común en el problema de la técnica y en el romanticismo, incluso aunque se deba, como interpreta Bredekamp, a razones opuestas. En tal sentido, este último autor subraya la conexión entre, por un lado, el vínculo en común con Albert Salomon -débil para Mehring, suficientemente fuerte, según Bredekamp, para que Salomon invite a Schmitt a unas conferencias en torno a la democracia y motive a Benjamin a enviarle la carta y el Trauerspiel-Buch al Jurist-, por el otro, resalta la anotación del 21/4/1930 en el diario de Benjamin: "Schmitt / Acuerdo odio sospecha" (cf. W. Benjamin, Gesammelte Schriften II/3, op. cit., p. 1372; W. Benjamin, Gesammelte Schriften VII/2, op. cit., p. 673; H. Bredekamp, "Walter Benjamin's Esteem for Carl Schmitt", op. cit., pp. 685-695; H. Bredekamp, "From Walter Benjamin to Carl Schmitt, via Thomas Hobbes", op. cit., pp. 250252; S. Heil, Gefährliche Beziehungen. Walter Benjamin und Carl Schmitt, Stuttgart, Metzler, 1996; C. Kambas, "Walter Benjamin an Gottfried Salomon: Bericht über eine unveröffentlichte Korrespondenz", en Deutsche Vierteljahrsschrift für Literaturwissenschaft und Geistesgeschichte 56, 1982, pp. 601-621; R. Mehring, "«Geist ist das Vermögen, Diktatur auszuüben»...”, op. cit., pp. 140-141). 
categorías schmittianas para pensar el drama barroco, se produce un desplazamiento fundamental. La función más importante del príncipe no será la de declarar el estado de excepción sino la de intentar excluirlo (ausschließen). ¿Qué significado posee este movimiento conceptual? Es necesario destacar aquí que el estado de excepción se encuentra ligado en este contexto a una noción de catástrofe como la caída del mundo en el abismo. En un brillante pasaje, el autor elabora este punto a partir de la alegoría como modalidad de conocimiento material:

Mientras que en el símbolo la transfiguración de la decadencia, el rostro transformado de la naturaleza se revela fugazmente a la luz de la redención, en la alegoría la facies hippocratica de la historia se ofrece a los ojos del observador como paisaje primordial petrificado. Todo lo que la historia desde el principio tiene de intempestivo, de doloroso, de fallido, se plasma en un rostro; o, mejor dicho: en una calavera. (...) Tal es el núcleo de la visión alegórica, de la exposición barroca y secular de la historia en cuanto historia de los padecimientos del mundo, el cual sólo es significativo en las fases de su decadencia ${ }^{30}$.

La alegoría es una herramienta epistemológica que permite dar cuenta de la marca de la caducidad propia de la noción de historia natural. Para Benjamin, constituye el elemento fundamental para repensar la naturaleza caída propia del barroco ${ }^{31}$. De allí la contraposición con el símbolo en tanto elemento clásico de la representación tradicional. Aún teniendo en cuenta que Benjamin sigue esbozando la posibilidad de una "resurrección", el proceso que caracteriza al barroco es el de la naturalización e inmanentización del mundo. Este movimiento conduce a una extrema tensión con la trascendencia y a la ausencia de una escatología $a^{32}$. En otras palabras, la trascendencia se encuentra absolutamente separada del mundo y ya no puede ser representada. Villacañas y García analizan las implicancias de dicha afirmación:

$30 \quad$ W. Benjamin, El origen del drama barroco alemán, trad. J. Muñoz Millanes, Madrid, Taurus, 1990, p. 159.

31 Para una profundización en la noción de alegoría y del rol que ocupa en el pensamiento de Benjamin, cf. S. Mosès, op. cit., p. 118 ss; F. Abadi y L. Espinosa, "La noción de muerte en la estética temprana de Walter Benjamin”, en Ágora. papeles de filosofia 33.2, 2014, pp. 167-183; y M. Molano "Walter Benjamin: historia, experiencia y modernidad", en Ideas y Valores 63.154, 2014, pp. 165-190.

32 Cabe señalar aquí la discusión iniciada por Agamben sobre la posibilidad de corregir la edición crítica del Trauerspiel-Buch. Es decir, reemplazar allí donde dice "keine barocke Eschatologie", por "eine barocke Eschatologie". Aunque consideramos que ambas posiciones parten de un consenso inicial en el cual se busca conceptualizar una catástrofe vacía - sin un contenido redentor determinado-, Agamben argumenta que se trata de una particular escatología que denomina "blanca" (cf. Agamben, op. cit., p. 73). Si bien esta interpretación parece alejarse de otros pasajes presentes en el mismo Trauerspiel$B u c h$, a lo que se suman indicaciones posteriores realizadas por Scholem, debe atenderse al potencial filosófico del análisis agambeniano. Éste se vincula con la distinción realizada en Il tempo che resta, a partir de la cual la escatología, como final del tiempo, se opone al mesianismo como tiempo del final (cf. G. Agamben, Il tempo che resta. Un commento alla "Lettera ai romani», Torino, Bollati Borighieri, 2000, p. 62). Cf. la interesante reconstrucción y lectura propuesta sobre el presente debate por F. Naishtat, “HHay una escatología barroca en el Trauerspielbuch? Agamben vs. Scholem", en Actas de las IX Jornadas de Investigación en Filosofía de la FHCE de la UNLP, 2013, pp. 1-11.
El Barroco percibe muy próxima la presencia de la transcendencia, pero la percibe como catástrofe, como ruina del mundo. $Y$ en este mismo acto subraya lo sensible como aquello que ha de hundirse en el abismo del fuego, como aquello que no ha de durar (...) Por eso el barroco carece de escatología: el mundo no puede salvarse sino desaparecer. La tesis filosófica de esta página es clara: el barroco saca a la luz las formas sensibles como lo que va a morir, a fin de subrayar el jorismós de la transcendencia. El cielo así se queda vacío, y al no reconocerse en ninguna forma sensible, las condena a todas ${ }^{33}$.

La paradoja que muestra el análisis benjaminano sobre el barroco consiste en que la soberanía exagera sus gestos y se aferra a ellos cuanto más vislumbra la imposibilidad de evitar la catástrofe. El carácter ineliminable de criatura propio del príncipe y su Forma Estado explican por qué jamás podrá tomar la decisión más extrema. No hay autoridad en la tierra que pueda instaurar o terminar un estado de excepción verdadero. En tal sentido, el príncipe se instala en el ámbito de la demora y de la vacilación en la toma de decisión: die Entschlussunfähigkeit. Su ascenso y caída sólo puede apuntar a construir una ilusión de "natural" permanencia de la soberanía a lo largo del tiempo ${ }^{34}$. Y es aquí donde puede encontrarse el antecedente para la inversión de la Tesis VIII: el estado de excepción ha devenido regla. Benjamin coloca la noción de historia en el núcleo de la reflexión en torno a esta resignificación de las nociones schmittianas de soberanía y de Repräsentation: "El soberano es el representante de la Historia. Sostiene el acontecer histórico en su mano como un cetro [Der Souverän repräsentiert die Geschichte. Er hält das historische Geschehen in der Hand wie ein Szepter]"35. Este pasaje nos permite avanzar hacia una cuestión fundamental de la lectura benjaminiana de Schmitt: la representación propia de la teoría de la soberanía implica la búsqueda por establecer una continuidad en el tiempo histórico $^{36}$. Villacañas y García refieren a la importancia de este núcleo argumentativo:

[L]a relación entre el soberano y la historia se teje en la forma de la representación. El soberano representa a la historia porque garantiza la continuidad del tiempo (...) Su enemigo radical es la catástrofe por la que se interrumpe el tiempo histórico (...) El soberano declara el estado de excepción, como Dios declara el fiat de

\footnotetext{
J. L. Villacañas y R. García, op. cit., pp. 48-9.

34 Como señala Samuel Weber, la antropología política y la tipología de las tres figuras que co-constituyen al drama barroco (tirano, mártir e intrigante) dan cuenta de este dislocamiento de la soberanía ya presente en el Trauerspiel-Buch (cf. S. Weber, op. cit., p. 9; W. Benjamin, El origen del drama barroco alemán, op. cit., pp. 42-87).

35 W. Benjamin, El origen del drama barroco alemán, op. cit., p. 50.

36 En "Die Sichtbarkeit der Kirche. Eine scholastische Erwägung", Schmitt ya había esbozado la conexión entre representación y continuidad temporal: “....nadie puede ignorar la mediación que conecta el acontecimiento histórico único de la encarnación humana de Cristo con el presente concreto, mediación que corresponde a la institución visible que sostiene el curso ininterrumpido de esa relación como tradición" (C. Schmitt, "La visibilidad de la Iglesia. Una reflexión escolástica”, trad. R. García, en Daimon. Revista de filosofia 13, 1996, pp. 11-18, aquí p. 14).
} 
la creación. Lo importante, sin embargo es que toda su obra tiende a crear el estado jurídico normalizado ${ }^{37}$.

Los desarrollos por parte de Schmitt, posteriores incluso a la muerte de Benjamin, no hacen más que confirmar, a nuestro juicio, la relevancia de esta discusión para comprender el pensamiento benjaminiano. Ya durante los años 30, Schmitt incorpora la noción de orden concreto a partir de la recuperación del pensamiento institucional de Maurice Hauriou pues, como él mismo repara en la Advertencia previa a la segunda edición de 1933 de Teología política, "el decisionista siempre está en peligro de perder en el carácter puntual del instante el ser estable contenido en todo gran movimiento político"38. Sin embargo, el teórico de Plettenberg aborda de forma explícita la discusión con Benjamin en su texto de 1956 Hamlet oder Hekuba. Der Einbruch der Zeit in das Spiel. Dicho libro contiene una propuesta metodológicapolítica para una comprensión histórica de la obra de Shakespeare. En este sentido, la lectura del autor consiste en afirmar la irrupción (der Einbruch) en Hamlet de la situación concreta de la época (die Zeit). Para Schmitt, el tumultuoso momento histórico, signado por la sucesión en Inglaterra de Elizabeth a James I, atraviesa y define la peculiar estructura de la obra y sus diferentes versiones. La incapacidad de decidir de los Stuarts en una época de crisis y conflicto religioso se introduce en el drama elevando el Spiel a la seriedad (Ernst) de la Tragödie (y a Hamlet a mito viviente).

Como señala con acierto en un artículo reciente David Pan, esta distinción se enraíza en la crucial oposición schmittiana entre norma y excepción. Es decir, por un lado el Spiel (en el sentido de drama y de juego) es entendido en tanto sistema coherente de reglas y procedimientos. Por el otro, la excepción de la tragedia no sólo irrumpe como una fuerza concreta y externa -un verdadero Ernstfall ("caso de emergencia")- sino también es la única que puede crear y, en última instancia, sostener la estructura metafísica interna de la representación propia del Spiel. En este sentido, el autor considera que, a pesar de las distancias, Römischer Katholizismus y Hamlet oder Hekuba ponen en escena una misma mirada sobre el problema de la representación ${ }^{39}$. Sin embargo, la interpretación de Schmitt a partir de la distinción entre Trauerspiel y Tragödie implica tanto una apropiación como un desplazamiento de las reflexiones benjaminianas del Trauerspiel-Buch. Cabe resaltar que la referencia a Benjamin en este texto ha sido ampliamente discutida. A partir de un riguroso análisis de cartas y de documentación disponible (especialmente las anotaciones de Schmitt en el libro sobre el Trauerspiel enviado por Benjamin), Mehring afirma que la atención que se ha colocado en esta conexión es exagerada, sobre todo si se la compara con los vínculos de Schmitt con otros

J. L. Villacañas y R. García, op. cit., p. 48.

38 C. Schmitt, Teología política, op. cit., p. 12. Para un desarrollo en Schmitt de esta cuestión y su formulación del pensamiento del orden concreto, cf. C. Schmitt, Über die drei Arten des rechtswissenschaftlichen Denkens, Hamburg, Hanseatische Verlagsanstalt, 1934.

39 Cf. D. Pan, "Tragedy as Exception in Carl Schmitt's Hamlet or Hecuba", en J. Meierhenrich y O. Simons (eds.), op. cit., pp. 731-750, aquí pp. 733-739. pensadores. El autor subraya que, para Schmitt, el debate con Benjamin resultaba un instrumento para romper con el aislamiento en el que se encontraba en el contexto de posguerra. Por su parte, Bredekamp reconoce este punto, aunque considera que de todos modos el interés de Schmitt en la lectura de Benjamin es legítimo ${ }^{40}$. En este sentido, resulta significativo tomar en consideración que en el excurso dedicado al filósofo berlinés, Schmitt rechaza el modo en el que las hipótesis benjaminianas enlazan, a partir de la concepción de providencia divina, las nociones de temporalidad, representación y gracia.

Para Schmitt, el error central de Benjamin consiste en interpretar el drama shakespereano desde un carácter cristiano en lugar de barbárico. El pensador de Plettenberg considera que Hamlet no pertenece al cristianismo tardomedieval pero tampoco puede inscribirse en el Estado moderno y en la concepción de la política que se desarrolla en el continente desde el siglo $\mathrm{XVI}^{41}$. Es por ello que la posición histórica de la obra permite distinguirla de las tragedias clásicas de Corneille y Racine propias de la soberanía esta-

40 Cf. H. Bredekamp, "Walter Benjamin's Esteem for Carl Schmitt", op. cit., p. 683; D. van Laak e I. Villinger (eds.), Nachlass Carl Schmitt: Verzeichnis des Bestandes im nordrhein-westfälischen Hauptstaatsarchiv (Veröffentlichungen der Staatlichen Archive $N R W$ - Reihe C), Siegburg, Respublica-Verlag, 1993, p. 386; M. Tielke, "Die Bibliothek Carl Schmitts", en Schmittiana N. F. Bd. I, 2011, pp. 257-332; R. Mehring, "«Geist ist das Vermögen, Diktatur auszuüben»...", op. cit., p. 149-152. Bredekamp argumenta que en los años de la publicación de Hamlet oder Hekuba - es decir, antes de la década de 1960-Benjamin había sido relativamente olvidado $\mathrm{y}$, a pesar de las nuevas ediciones y publicaciones, no era conocido fuera de los círculos de Adorno y de Scholem. Cf. H. Bredekamp, "Der simulierte Benjamin: Mittelalterliche Bemerkungen zu seiner Aktualität", en A. Berndt et al (eds.) Frankfurter Schule und Kunstgeschichte, Berlin, Reimer Verlag, 1992, pp. 117-140, aquí pp. 120-122; M. Tielke, op. cit., pp. 270-272; T. Küpper y T. Skrandies, "Rezeptionsgeschichte", en B. Lindner (ed.) Benjamin-Handbuch: Leben-Werk-Wirkung, Stuttgart, Metzler, 2006, pp. 17-56. Para Bredekamp, esta posición puede reforzarse aún más teniendo en cuenta las diferentes anotaciones en el Trauerspiel-Buch realizadas por Schmitt. Cabe señalar que este no es el único texto comentado por Schmitt, puesto que entre los libros de Benjamin que pertenecen a su biblioteca (registrados en el Nachlass) se hallan anotados también Goethes Wahlverwandtschaften, Ausgewählte Schriften [1]. Illuminationen y Das Kunstwerk im Zeitalter seiner technischen Reproduzierbarkeit (los libros en total con autoría de Benjamin, esto es, sin contar los textos sobre el filósofo berlinés, están registrados en: Landesarchiv Nordrhein-Westfalen Abt. Rheinland, Düsseldorf, Nachlass Carl Schmitt - LAV NRW RW 265 - Números: 29012; 26567; 26566; 26568; 26739; 25722; 26565). Ahora bien, el centro de dicha discusión se encuentra precisamente en los comentarios al libro que motivó la epístola, por extensión, complejidad e intensidad. En este sentido, vale subrayar que Mehring afirma: "En todo momento, [Schmitt] habría negado cualquier influencia de Benjamin en su obra. Incluso el Trauerspiel-Buch, que Benjamin envió, probablemente fue leído recién después de 1945” (R. Mehring, "«Geist ist das Vermögen, Diktatur auszuüben»...", op. cit., p. 139). Bredekamp, por su parte, sostiene que las anotaciones: "muestran un acercamiento sin compromisos que combina palabras de alta valoración con frases de crítica. Más importante aún, ellos revelan tres estilos diferentes de comentarios, el primero de los cuales obviamente surge de la primera lectura en 1930" (H. Bredekamp, "Walter Benjamin's Esteem for Carl Schmitt”, op. cit., p. 697). En relación con este debate, cf. también J. Thaler, "Genial. Carl Schmitt liest Walter Benjamin", en M. Atze y V. Kaukoreit (eds.) Lesespuren-Spurenlesen oder Wie kommt die Handschrift ins Buch? Von sprechenden und stummen Annotationen, vols. 12/13, Wien, Praesens, 2013, pp. 246-251.

41 Cf. C. Schmitt, Hamlet o Hécuba. La irrupción del tiempo en el dra$m a$, trad. R. García, Valencia, Pre-Textos/Universidad de Murcia, 1994 , p. 51 ss. 
tal moderna. El elemento representativo que se encuentra al interior de la categoría de Spiel y de la teatralización barroca de la vida isabelina no se identifica, según Schmitt, con la representación que ve al mundo a partir del ojo del soberano propio de la estatalidad moderna. Tampoco es la mirada del teatro social del siglo XIX. En este caso, la autonomía propia del drama shakespeareano hace posible la emergencia del Zeit en el drama. De allí el lugar central que ocupa, desde el título, la oposición entre Hamlet y Hécuba. En el contexto de un orden tradicional en disolución, los Stuarts (y James I en particular) se aferran a la antigua concepción del poder divino del rey. El autor alemán considera que la indecisión del príncipe habla aquí de la incapacidad de asumir el re-orientamiento que Inglaterra emprenderá ante la catastrófica des-orientación que signa la guerra civil religiosa. Para Schmitt, la respuesta específica de Inglaterra ante esta época crítica significará la afirmación de Inglaterra de una existencia marítima. Aquí se encuentra el núcleo de la crítica schmittiana a Benjamin. Según Schmitt, el carácter no-cristiano (barbárico) del drama shakespereano puede distinguirse con precisión si se atiende a la condición insular de Inglaterra frente a la soberanía terrestre del continente $-\mathrm{y}$, por lo tanto, si se atiende asimismo a la problemática político-estatal presente en el Trauerspiel alemán ${ }^{42}$.

Ahora bien, como señala Galli con justeza en la presentación a la edición italiana de 1983 de Hamlet oder Hekuba, esta discusión no puede comprenderse cabalmente si no se recuperan las categorías que años antes Schmitt había desarrollado centralmente en Land und Meer (Tierra y mar, de 1942) y en Der Nomos der Erde im Völkerrecht des «Jus Publicum Europaeum» (El Nomos de la Tierra en el Derecho de Gentes del «Jus Publicum Europaeum», de 1950) ${ }^{43}$. En este último libro, Schmitt desarrolla la fuerza que "supo sostener" la continuidad y la unidad de la Respublica Christiana: "Imperio [Reich] significa en este contexto la fuerza histórica que es capaz de detener [aufzuhalten] la aparición del Anticristo y el fin del eón presente, una fuerza qui tenet,

42 Cf. C. Schmitt, Hamlet o Hécuba, op. cit., pp. 53-54.

43 Cf. C. Galli, "Presentazione dell'edizione italiana", en C. Schmitt, Amleto o Ecuba: L'irrompere del tempo nel gioco del dramma, trad. S. Forti, Bologna, Il Mulino, 1983, pp. 7-35, aquí p. 15; C. Schmitt, Land und Meer: Eine weltgeschichtliche Betrachtung, Leipzig, Reclam Verlag, 1942; C. Schmitt, Der Nomos der Erde im Völkerrecht des «Jus Publicum Europaeum», Köln, Greven Verlag, 1950. Con respecto al debate en torno a la tragedia como género dramático, Galli propone comprender los contornos de esta discusión alemana a partir de las figuras de Hegel, Schelling y Hölderlin (cf. C. Galli, "Presentazione dell'edizione italiana", op. cit., p. 23 ss). En relación a la crítica de Schmitt a Benjamin en el Excursus, no deja de ser llamativo que los propios textos del Jurist que comienzan a centrarse en esta cuestión son muy posteriores a la escritura y a la publicación del libro sobre el Trauerspiel. Se trata de temáticas que fueron desarrolladas en publicaciones no sólo posteriores al exilio sino también a la muerte de Benjamin. Por otro lado, podría afirmarse que ciertas críticas del pensador de Plettenberg al Trauerspiel-Buch podrían redirigirse al propio Schmitt de la época de Weimar. Si bien no podemos extendernos aquí a analizar exhaustivamente las implicancias de las continuidades y divergencias que se producen en el pensamiento schmittiano de la época (tarea a la que nos abocaremos en próximos trabajos) buscamos desarrollar en este texto los que consideramos son los núcleos centrales para avanzar en la comprensión de la crítica benjaminiana a Schmitt en torno a las problemáticas de la representación y del tiempo histórico. Igualmente, sobre la crítica schmittiana a partir de las nociones de tierra y mar, cf. R. Mehring, "«Geist ist das Vermögen, Diktatur auszuüben»...”, op. cit., pp. 150-151. según las palabras del apóstol Pablo en la segunda Carta de los Tesalonicenses, capítulo 2"44. Reintroduciendo la figura del katechon en el debate filosófico-político a través de la referencia paulina de 2 Tes 6-7, el autor coloca el acento en esta paradójica categoría paulina: el katechon no sólo frena y contiene la venida del ánomos sino que, con ello, también impide el advenimiento de la parousía. En un breve artículo de la época, "Drei Möglichkeiten eines christlichen Geschichtsbildes" ("Tres posibilidades de una visión cristiana de la Historia", de 1950), Schmitt reflexiona sobre la supuesta incompatibilidad entre la fe escatológica y una conciencia histórica. En otros términos, el autor se pregunta si es acaso posible evitar la parálisis histórica que genera dicha fe. Resulta significativo el modo en el que Schmitt responde en las líneas subsiguientes:

La viva espera del fin inmediato parece privar de su sentido a toda la historia y provoca una parálisis escatológica, de la que existen numerosos ejemplos históricos. A pesar de ello, hay también la posibilidad de tender un puente. De ello tenemos ejemplos asombrosos en la historia del imperio medieval. El puente lo viene a constituir la idea de una fuerza que detiene el advenimiento del fin y reprime

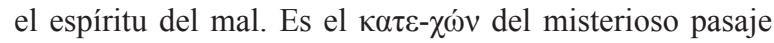
de San Pablo en la segunda epístola a los tesalonicenses ${ }^{45}$.

La interpretación en torno al katechon ha suscitado -tanto históricamente como en la actualidad-diferentes abordajes teológicos y filológicos para dilucidar cuál podría ser aquello a lo que refiere San Pablo con esta figura. Sin embargo, ha sido precisamente Taubes uno de los principales autores que ha comenzado a desarrollar el alcance filosófico de esta lectura schmittiana ${ }^{46}$. En este sentido, Taubes ha establecido una contraposición con Schmitt basada en una cercanía extrema. El autor considera que hay un punto de vista común que los une al mismo tiempo que los separa: "Cabe leer a Schmitt tanto como jurista cuanto como apocalíptico de la contrarrevolución (...) Como apocalíptico que soy, me sabía y me sé próximo a él. Los temas nos son comunes, aunque extraemos consecuencias de tendencia opuesta"47. El autor advierte en Schmitt una posición que caracteriza como propia del "jurista" (lo cual implique quizás un guiño hacia "Para una crítica de la violencia"). Es decir, frente

C. Schmitt, El Nomos de la Tierra en el Derecho de Gentes del "Jus Publicum Europaeum”, trad. D. Schilling, Buenos Aires, Ed. Struhart \& Cía, 2005, p. 40.

45 C. Schmitt, "Tres posibilidades de una visión cristiana de la Historia”, en Arbor 62.II, 1951, pp. 237-241, aquí 239.

46 Cf. H. Bredekamp, "From Walter Benjamin to Carl Schmitt, via Thomas Hobbes", op. cit., p. 248. En relación con las lecturas que colocan la noción de katechon como núcleo central para la comprensión del pensamiento de Schmitt, cf. G. Meuter, Der Katechon: Zu Carl Schmitts fundamentalistischer Kritik der Zeit, Berlin, Duncker \& Humblot, 1994; F. Grossheutschi, Carl Schmitt und die Lehre vom Katechon, Berlin, Duncker \& Humblot, 1996; T. Paléologue, Sous l'oeuil du grand inquisiteur: Carl Schmitt et l'heritage de la theologie politique, Paris, Editions du Cerf, 2004; J. Hell, "Katechon: Carl Schmitt's Imperial Theology and the Ruins of the Future", en The Germanic Review 84.4, 2009, pp. 283-326; M. Lievens, "Carl Schmitt's Concept of History", en J. Meierhenrich y O. Simons (eds.), op. cit., pp. 401-425.

47 J. Taubes, La teología política de Pablo, trad. M. García-Baró, Madrid, Trotta, 2007, p. 165. 
a la amenaza de la anarquía, el jurista busca reafirmar e interpretar el Derecho tal como le es dado. Se trata de una posición que implica sostener la legitimidad del Estado y evitar por todos los medios posibles el ascenso del caos. De este modo, Taubes resume en el siguiente pasaje su interpretación en relación al peculiar vínculo que lo une con el Jurist:

Carl Schmitt piensa en términos apocalípticos pero desde arriba, desde las potencias; yo pienso en términos apocalípticos pero desde abajo. Pero los dos tenemos en común la experiencia del tiempo y la historia como plazo, como plazo perentorio. Y ésta es en su origen una experiencia cristiana de la historia ${ }^{48}$.

La última línea resulta esclarecedora para la pregunta que nos habíamos realizado al inicio del apartado. Una experiencia cristiana de la historia implica una lectura de la escatología y del tiempo histórico que tiene a su base una perspectiva cronológica tradicional. Que el final de la historia no haga hincapié en el Reino de los Cielos sino en el advenimiento del Apocalipsis no altera su estructura. Si el Estado es concebido desde su rol " $k a$ techóntico", no sólo la parálisis escatológica es evitada, sino que el supuesto retorno a la "normalidad" se nos revela como una ilusión absolutamente imposible. En El Nomos de la Tierra, Schmitt afirmaba: "Lo fundamental de este imperio cristiano es el hecho de que no sea un imperio eterno, sino que tenga en cuenta su propio fin y el fin del eón presente, y a pesar de ello sea capaz de poseer fuerza histórica"49.

Una vez realizado este desarrollo, podemos abordar ahora por qué el estado de excepción schmittiano es considerado por Benjamin como lo opuesto de "wirklich" (tanto en el sentido de "no-verdadero" como en el de "no-efectivo"). Aun cuando Schmitt resalta el instante de la decisión, la estructura temporal de su estado de excepción implica la reconstrucción de una continuidad a lo largo de una línea de tiempo. Si bien ya hemos abordado las cercanías que pueden plantearse entre ambos autores sobre dicha noción de instante (rigurosamente estudiadas por Bredekamp ${ }^{50}$ ), consideramos que es necesario precisar en qué sentido Benjamin se propone desmontar la concepción schmittiana del tiempo. En otros términos, se trata de analizar la apuesta de Benjamin por evitar la reinscripción del instante a los términos tradicionales de la continuidad. La interpretación schmittiana sobre la irrupción reintroduce el mito trágico en el surgimiento del proceso de secularización (en su faceta de neutralización técnico-económica y desarraigo). Por el contrario, la noción de interrupción de las Tesis reafirma lo que Benjamin buscaba explicitar en la concepción de la historia que emergía en el Trauerspiel. Es decir: el punto de partida para una crítica de Schmitt consiste en señalar la imbricación entre el problema de la representación con su concepción del tiempo. Esta posición filosófica vertebra la lectura que el filósofo berlinés realiza en las Tesis de la noción de estado de excepción schmittiano. ¿Qué lugar ocupa

\footnotetext{
$48 \quad$ Ibidem, p. 169.

49 C. Schmitt, El Nomos de la Tierra ..., op. cit., p. 40.

50 Cf. H. Bredekamp, "From Walter Benjamin to Carl Schmitt, via Thomas Hobbes", op. cit., pp. 250-252; H. Bredekamp, "Walter Benjamin's Esteem for Carl Schmitt”, op. cit., pp. 686-693.
}

entonces la escatología en Schmitt? Postular que el Estado no es eterno, que el Leviatán es un Deus mortalis, resulta para Schmitt la condición de posibilidad para asegurar su continuidad y duración ${ }^{51}$. La posición de Schmitt supone el comienzo y el fin del estado de excepción como puntos equi-valentes y re-presentables en una línea homogénea. Sin embargo, a su vez, esta cadena de "ahoras", unívocamente orientada al futuro, debe contener necesariamente la amenaza ineluctable de su destrucción. En otros términos, la concepción de Schmitt de la experiencia cristiana de la escatología no pone en cuestión la temporalidad técnica de los relojes. Invirtiendo la perspectiva de la socialdemocracia que Benjamin describe en la Tesis XVIIa respecto a la secularización del tiempo mesiánico ${ }^{52}$, puede afirmarse que el Estado schmittiano tiene como "tarea infinita", al interior de un tiempo vacío, contener el caos. En otras palabras, la tradición de los oprimidos muestra para Benjamin la ficción propia de la perspectiva schmittiana que afirma como posible una suspensión temporal del Derecho. En este sentido es posible comprender la pretensión de asegurar un continuum histórico en el que el instante de la decisión excepcional pueda durar en la norma. En los términos de "Para una crítica de la violencia" dicha perspectiva supone las condiciones estructurales para la reproducción del círculo de violencia y Derecho.

Ahora bien, ya hemos señalado que en aquel ensayo de 1921, Benjamin proponía una salida a este círculo mítico a través una violencia divina "irrepresentable". Frente al "concepto límite" (Grenzbegriff) de Schmitt, Benjamin no sólo pensaba en una categoría extra-normativa sino también extra-jurídica. Un más allá del Derecho. Sin embargo, esto implica también la necesidad de una reformulación de las categorías de tiempo y de instante que impida su reinscripción en una noción tradicional de continuidad. Ahora bien, el modo en el que esta otredad heterogénea podía irrumpir en el presente como experiencia histórica, sin ser capturada por el dispositivo de la representación tradicional, aparecía en dicho texto de modo esquemático. En ese sentido, quizás podamos interpretar las posteriores investigaciones epistemológicas y metodológicas emprendidas por Benjamin como una búsqueda en pos de la articulación

\footnotetext{
Schmitt señala en las cartas del 4 de abril y 11 de mayo de 1973 a Hansjörg Viesel que sus conocidos textos sobre Hobbes de 1937 y 1938 fueron en verdad respuestas al Trauerspiel-Buch de Benjamin que pasaron desapercibidas (cf. H. Viesel, Jawohl, der Schmitt: Zehn Briefe aus Plettenberg, Berlin, Support Edition, 1988, pp. 14; 6061). Más allá de la lectura, nuevamente estratégica, que pueda tener esta referencia por parte de Schmitt, no deja de ser sugerente, por una parte, el análisis schmittiano de la extrema centralidad del carácter simbólico del Leviatán. Por otra parte, cabe señalar que Mehring ha buscado precisamente delimitar en su análisis, tanto el lugar que ocupa para Schmitt el problema de la alegoría y la lectura cristiana del Antiguo Testamento, como así también la relevancia de las anotaciones sobre el Leviatán que Schmitt escribe en su ejemplar del libro sobre el Trauerspiel (Walter Benjamin, Ursprung des deutschen Trauerspiels, Berlin, 1928, LAV NRW RW 265, N²9012): “¡Falta el Leviatán!”, “iipor cierto él también falta en el escenario alemán!!”, “Ninguna palabra sobre el Leviatán!” (cf. R. Mehring, “"Geist ist das Vermögen, Diktatur auszuüben»...”, op. cit., pp. 144-152). Cf. también sobre estas temáticas H. Bredekamp, "Walter Benjamin's Esteem for Carl Schmitt”, op. cit., pp. 684-694; y H. Bredekamp, Thomas Hobbes: visuelle Strategien. Der Leviathan: Urbild des modernen Staates. Werkillustrationen und Portraits, Berlin, Akademie Verlag, 1999.

52 Cf. W. Benjamin, "Sobre el concepto de historia", op. cit., p. 275.
} 
de este problema. Esta indagación iría desde la concepción monadológica del Erkenntniskritische Vorrede ("Prólogo crítico-epistemológico") del Trauerspiel-Buch hasta la tarea del historiador materialista en el Passagen-Werk y en las Tesis "Sobre el concepto de historia" 53 . No podemos olvidar que los apuntes preparatorios para las Tesis, incluidos en el Konvolut $\mathrm{N}$ de la Obra de los pasajes, cuentan con el título: "Teoría del conocimiento, teoría del progreso".

\section{Memoria e imagen dialéctica: hacia nuevas categorías de tiempo y de historia}

Si bien la discusión explícita en torno a la noción de Ausnahmezustand se encuentra en la Tesis VIII, el texto de Benjamin comienza previamente a hilvanar su apuesta por una filosofía política de la historia. De esta manera, la Tesis VI puede considerarse un rico punto de partida para comenzar a desarrollar el escorzo que podemos denominar, por mor expositivo, pars construens. Sin embargo, está claro que en la argumentación benjaminiana no se da una distinción abstracta de estos momentos sino un complejo trabajo compositivo de constelaciones y yuxtaposiciones que buscan repensar las categorías de representación, tiempo e historia. La noción de instante de peligro (Augenblick der Gefahr) nos permite comprender con mayor claridad las dificultades que esperan al historiador materialista que se propone revelar el estado de excepción permanente y recuperar las enseñanzas de la tradición de los oprimidos. Este esfuerzo requiere, como se desarrolla en la Tesis siguiente (VII), romper con la empatía con el vencedor. Cimentar la "tradición de los oprimidos" implica una nueva mirada que, a través del distanciamiento ${ }^{54}$, pueda hacer saltar por los aires el continuum del cortejo triunfal $^{55}$. La alegoría del Angelus Novus ocupa un lugar crucial en la descripción del progreso como acumulación de ruina sobre ruina. La imagen desoladora del huracán

53 En esta búsqueda filosófica, Benjamin trabaja una serie de nociones que, por cuestiones de espacio, no podremos desarrollar en profundidad en este trabajo. Quisiéramos destacar de todos modos la importancia que posee la tematización sobre el lenguaje y la traducción en su vínculo con la problemática de la redención y la justicia, que parte desde el temprano escrito de 1916 ("Über Sprache überhaupt und über die Sprache des Menschen"), pasando por "Die Aufgabe des Übersetzers" (1923) y "Der Autor als Produzent" (1934). Juan Mayorga Ruano afirma que el ensayo del '16 contiene elementos fundamentales para una "política del lenguaje benjaminiano" (cf. J. Mayorga Ruano, Revolución conservadora y conservación revolucionaria. Política y memoria en Walter Benjamin, Barcelona, Anthropos Editorial/UAM-Iztapalapa-México, 2003, p. 27). Para un análisis de este nexo, en relación con la apropiación benjaminiana de la noción de mónada de Leibniz, cf. G. Catanzaro, “Justicia y Monadología: el roce entre el materialismo benjaminiano y la metafísica de Leibniz en la Crítica del Conocimiento", en Anacronismo e Irrupción. Revista de Teoría y Filosofía Política Clásica y Moderna 2.2, 2012, pp. 170-204.

54 No es casual que Benjamin coloque como epígrafe de esta Tesis una cita de Bertolt Brecht, planteando un interesante vínculo con su noción de Verfremdungseffekt. Si bien no podemos profundizarlo aquí, para un análisis comparativo que aborde esta noción de alejamiento que permite al espectador un punto de vista crítico, cf. M. Polgovsky Ezcurra, "On «Shock»: The Artistic Imagination of Benjamin and Brecht", en Contemporary Aesthetics 10, 2012, pp. 1-10.

55 Cf. W. Benjamin, "Sobre el concepto de historia", op. cit., pp. 129130. que contempla el Ángel se vincula directamente con el estado de excepción permanente. De hecho, en [N9, a1] encontramos que Benjamin sostiene: "Hay que basar el concepto de progreso en la idea de catástrofe. Que esto «siga sucediendo» es la catástrofe" ${ }^{56}$. La ruina no está en un Apocalipsis futuro que amenaza con destruir el orden sino todo lo contrario: ésta sucede aquí y ahora. Es por ello que para Benjamin la revolución consiste en interrumpir la continua realización de la catástrofe, en accionar el "freno de emergencia" 57 .

Si la tradición de los oprimidos es lo otro de la Historia Universal y del progreso, la posibilidad del historiador materialista de dar cuenta de su historia debe encontrarse en la dialektisches Bild ("imagen dialéctica") como crítica radical de la representación tradicional. La teoría benjaminiana no concibe al conocimiento como un ámbito abstracto e inmutable sino que su misma posibilidad se presenta en el momento de su legibilidad (Lesbarkeit), tal como el autor escribe en [N3, 1] del Konvolut $\mathrm{N}^{58}$. La apuesta filosófica de Benjamin en este punto, como afirma en [N 11, 4], consiste en que la historia se descompone en imágenes ${ }^{59}$. Para Benjamin, esta operación implica traer al presente aquello que es irrepresentable o, siguiendo la sugerencia de Hugo von Hofmannsthal, leer lo que nunca fue escrito ${ }^{60}$.

Este presente ya no puede concebirse como una transposición del tiempo físico, causalmente determinado, sino como un presente densificado, en el cual se encuentra siempre latente la posibilidad de la interrupción mesiánico-revolucionaria. Si la historiografía tradicional presenta una continuidad de ahoras enhebrados "como un rosario entre los dedos", la imagen dialéctica benjaminiana propone un salto de tigre (Tigersprung) entre pasado y presente. Es por ello que la noción de origen (Ursprung) resulta aquí absolutamente reformulada, como lo muestra el epígrafe de Karl Kraus en la Tesis XIV ("El origen es la meta"). No se trata de una recuperación aséptica del pasado primigenio sino de una creación novedosa que arranca las citas de su contexto previo. Para Benjamin, lo histórico es el salto constituido por la imagen dialéctica en un tiempo "lleno" de Jetztzeit (tiempo-ahora). Las posibilidades irredentas permanecen latentes aguardando el ahora de su cognoscibilidad. Ello significa que la noción benjaminia-

W. Benjamin, Libro de los pasajes, trad. L. Fernández, I. Herrera y F. Guerrero, Madrid, Akal, 2007, p. 476.

57 Cf. [Ms-BA 1100], W. Benjamin, "Materiales preparatorios del escrito", op. cit., p. 307.

58 Benjamin desarrolla en [N 3, 1]: “...el índice histórico de las imágenes no sólo dice a qué tiempo determinado pertenecen, dice sobre todo que sólo en un tiempo determinado alcanzan legibilidad (...) No es que lo pasado arroje luz sobre lo presente, o lo presente sobre lo pasado, sino que imagen es aquello en donde lo que ha sido se une como un relámpago al ahora en una constelación. En otras palabras: imagen es la dialéctica en reposo (...) La imagen leída, o sea, la imagen en el ahora de la cognoscibilidad, lleva en el más alto grado la marca del momento crítico y peligroso que subyace a toda lectura" (W. Benjamin, Libro de los pasajes, op. cit., p. 465).

59 Cf. Ibidem, p. 478.

60 Cf. [Ms-BA 470], en W. Benjamin, "Materiales preparatorios del escrito", op. cit., p. 313. Cf. sobre esta cuestión P. Kuffer Dinerstein, "«Leer lo que nunca fue escrito»: hacia una hermenéutica política", en Ágora: Papeles de Filosofia 34/1, pp. 213-221.

${ }_{61}$ W. Benjamin, "Sobre el concepto de historia", op. cit., p. 293. 
na de Eingedenken implica la apuesta por una efectiva redención de aquellas generaciones oprimidas que han quedado sepultadas por "el continuum de los opresores (...) La conciencia de una discontinuidad histórica es lo propio de las clases revolucionarias en el momento de su acción" [Ms-BA 469] $]^{62}$. En su comentario a las Tesis, Reyes Mate resalta esta prioridad de lo que pudo haber sido por sobre lo dado. Esta inversión de la perspectiva histórica es leída por el autor como una apropiación crítica de la noción de memoria ${ }^{63}$. En efecto, el filósofo berlinés afirma en [Ms-BA 474]:

La imagen del pasado que relampaguea en el ahora de la cognoscibilidad es, en una aproximación más precisa, una imagen de la memoria. Se parece a las imágenes del propio pasado que le vienen al hombre en un momento de peligro (...) De ahí que la historia sea en sentido estricto una imagen proveniente de una recordación involuntaria ${ }^{64}$.

En un ensayo sobre la fantasmagoría en la obra de Benjamin, Margaret Cohen subraya que uno de los proyectos metodológicos más importantes del PassagenWerk consistiría en desligar del análisis marxista su tradicional valorización de lo que constituyen las formas racionales de la representación ${ }^{65}$. Así, el principio de construcción benjaminiano implica un montaje y yuxtaposición de distintos elementos arrancados de su contexto. El rechazo de la representación tradicional ("simbólica" según el Trauerspiel-Buch) no implica una superación dialéctica que apunta a lo absoluto, sino aquello que Benjamin denomina Dialektik im Standstill ("dialéctica en suspenso" o "en reposo"). Por lo tanto, se trata de reunir los fragmentos en tensión en una constelación que permita arrancar el pasado irredento de la narración continuista del progreso.

En el Exposé de 1935, Benjamin describía las imágenes oníricas que fragmentan toda experiencia e impiden el "despertar" 66 . Resulta necesario transfigurar los sentidos pregnantes en las mercancías de la cultura de masas, tomando esas imágenes oníricas del capitalismo decimonónico para convertirlas en dialécticas. Susan Buck-Morss ha realizado una tarea muy destacada en el análisis de esta cuestión a medida que los textos póstumos de Benjamin comenzaban a publicarse en ediciones críticas (sobre todo, pero no solamente, el monumental Passagen-Werk). Esta autora ha indagado sobre el paralelismo que podemos establecer entre dos pares conceptuales. Por un lado, las nociones de sueño colectivo e historiografía historicista entendidas como continuidad. Por el otro, la interrupción propia del despertar de

\footnotetext{
W. Benjamin, "Materiales preparatorios del escrito", op. cit., p. 311. Cf. R. Mate, op. cit., p. 119.

4 W. Benjamin, "Materiales preparatorios del escrito", op. cit., p. 317.

65 Cf. M. Cohen, "La fantasmagoría de Walter Benjamin", en A. Uslenghi (comp.), Walter Benjamin: Culturas de la imagen, trad. S. Villegas, Buenos Aires, Eterna Cadencia Editora, 2010, pp. 207-236, aquí p. 208.

66 Esta cuestión nos reenvía al análisis de la noción de experiencia realizado por Benjamin. Si bien excede los límites de este trabajo, cabe destacar su desarrollo en "Erfahrung und Armut (1933) y "Über einige Motive bei Baudelaire" (1939). Para una profundización en torno a la distinción conceptual entre la mera Erlebnis y la posibilidad de reconstruir una Erfahrung, cf. M. Molano, op. cit., pp. 173-177.
}

la imagen dialéctica como método para la historiografía materialista. La autora afirma:

[E]l objetivo de Benjamin (...) era conectar el shock del despertar con la disciplina del recordar y así movilizar a los objetos históricos (...) astucia es la capacidad, a través del despertar, de burlar a la historia que ha puesto un hechizo en el sueño colectivo y ha mantenido inconscientes a sus miembros ${ }^{67}$.

La imagen dialéctica constituye un conocimiento político porque establece una constelación que se encontraba en el pasado inconsciente y silenciado de las generaciones oprimidas. La mimesis es entendida aquí en un sentido eminentemente creativo, opuesto a la búsqueda de una representación aséptica que lo relate "tal cual fue". El shock del montaje benjaminiano no busca suturar los fragmentos con el objetivo de generar una ilusión de continuidad. Por el contrario, el impulso mimético asume el gesto infantil que produce nuevos sentidos. El carácter teórico-práctico de esta tarea constituye por tanto una praxis histórico-politica ${ }^{68}$.

Benjamin opone el principio constructivo de la historiografía materialista al método aditivo del historicismo. "La historia de los oprimidos, un discontinuum" puede leerse en [Ms-BA 469 $]^{69}$. En este contexto, las implicancias políticas de la reformulación conceptual son presentadas con claridad por Benjamin en la Tesis XVII:

Cuando el pensamiento se detiene de repente en una constelación saturada de tensiones, provoca aquél en ésta una sacudida en virtud de la cual la constelación cristaliza en mónada (...) En esa estructura él reconoce el signo de una suspensión mesiánica del acontecer o, dicho de otra manera, de una oportunidad revolucionaria en la lucha por el pasado oprimido ${ }^{70}$.

La estructura monadológica del conocimiento resulta para Benjamin la posibilidad de pensar desde el materialismo el instante fugaz de legibilidad en el que la historia se abrevia en una singularidad ${ }^{71}$. La venida del Mesías no es para Benjamin el punto final de un desarrollo lineal sino una suspensión, una irrupción que se inscribe en la historia. Cada generación cuenta con una débil fuerza mesiánica ${ }^{72}$, cada presente, entendido como Jetztzeit, posee incrustadas astillas del tiempo mesiáni-

\footnotetext{
S. Buck-Morss, The Dialectics of Seeing. Walter Benjamin and the Arcades Project, Cambridge, The MIT Press, 1989, pp. 272-273, énfasis original.

68 Tomando en cuenta este punto, Michael Löwy considera: "La alternativa que propone es, a la vez y de manera inseparable, histórica y política. Parte de la hipótesis de que cada momento histórico tiene potencialidades revolucionarias. Se trata de oponer una concepción abierta de la historia como praxis humana, rica en posibilidades inesperadas y capaz de producir lo nuevo, a toda doctrina teleológica confiada en las «leyes de la historia» o la acumulación gradual de reformas en el camino seguro y garantizado del Progreso infinito" (M. Löwy, Walter Benjamin. Aviso de incendio, trad. H. Pons, Buenos Aires, FCE, 2002, p. 119).

69 W. Benjamin, "Materiales preparatorios del escrito", op. cit., p. 311.

70 W. Benjamin, "Sobre el concepto de historia", op. cit., p. 261.

71 Cf. G. Catanzaro, op. cit., p. 200.

72 Cf. Tesis II (W. Benjamin, "Sobre el concepto de historia", op. cit., p. 67).
} 
$\mathrm{co}^{73}$. Pero su interpretación del mesianismo se separa de una perspectiva escatológica que profetiza un futuro final de la historia. En el Fragmento B, último texto de las Tesis, Benjamin condensa este vínculo entre mesianismo y Eingedenken:

Sabido es que a los judíos les estaba prohibido escrudiñar el futuro. La Torá y la oración les instruyen, por el contrario, en la recordación. Ésta desencantaba el futuro, al que sucumbían cuantos buscaban respuestas en los adivinos. Pero no por eso se convirtió el futuro para los judíos en un tiempo homogéneo y vacío, porque en ese futuro cada segundo era la pequeña puerta por la que podía entrar el Mesías $^{74}$.

Frente al futuro de los adivinos y frente a la Historia Universal de los "grandes personajes", la construcción histórica benjaminiana apunta a la difícil tarea de recordar y salvar a los que han fracasado una y mil veces. En otras palabras, a través de la noción de Jetztzeit, la memoria de lo que pudo ser cobra todo su sentido históricopolítico en relación con el problema de la representación. En el siguiente y último apartado analizaremos las consideraciones finales en torno a esta cuestión.

\section{Consideraciones finales}

A lo largo de este trabajo nos propusimos desplegar en profundidad el alcance de la crítica plasmada en las Tesis, por parte de Benjamin, al pensamiento schmittiano. Postulamos como hipótesis la relevancia del problema de la representación al interior de dicha crítica y su vínculo con el análisis benjaminiano de la concepción tradicional del tiempo y de la historia.

Con el fin de seguir dicho hilo conductor, comenzamos desarrollando la inversión que el filósofo berlinés realiza sobre la noción de estado de excepción elaborada por Schmitt. A partir de la exégesis de la Tesis VIII nos preguntamos por la singularidad del wirkliche Ausnahmezustand planteado por Benjamin. Dicho interrogante nos condujo a su artículo "Para una crítica de la violencia" en tanto importante antecedente conceptual para la disputa con el pensador de Plettenberg. La crítica a la representación contenida en dicho texto marca un hiato fundamental en los puntos de vista de ambos autores. Mientras que uno (Schmitt) busca sostener al Derecho a través de una noción eminente de representación ( $R e$ präsentation), el otro (Benjamin) considera necesario poner en cuestión el vínculo entre violencia y Derecho a través de una noción de violencia divina que no pueda ser capturada por el Derecho en tanto dispositivo de la representación. Para Benjamin, sólo una fuerza absolutamente heterogénea e irrepresentable es capaz de interrumpir la continua oscilación entre violencia fundadora y conservadora de Derecho. Para Schmitt, la pregunta se dirige en cambio a pensar las condiciones en las que es posible sostener el orden estatal y su soberanía. Es por ello que aun cuando sus nociones aborden fenómenos

\footnotetext{
Cf. Fragmento A (Ibidem, pp. 293-294)

74 Ibidem, p. 297.
}

extra-normativos (como lo es la decisión sobre el caso excepcional) permanecen, en tanto conceptos límites (Grenzbegriffe), en el ámbito de lo jurídico. Su categoría de Repräsentation busca hacer visible la trascendencia a través de una máxima autoridad personal (el soberano). La analogía estructural con la Iglesia sigue este propósito de una unidad política duradera. En tal sentido, el desarrollo nos condujo a poner en discusión las nociones tradicionales de tiempo, historia y representación que atraviesan el pensamiento schmittiano.

En el segundo apartado nos abocamos a dilucidar dicha cuestión. Consideramos que es en este contexto filosófico donde Benjamin parte de una crítica de la representación, compartida con Schmitt, para dirigirse hacia la reformulación de las nociones de tiempo e historia tradicionales en las que permanecen atrapadas las categorías del Jurist. A partir de la lectura en torno al Trauerspiel-Buch y a la profundización realizada en textos posteriores, analizamos en qué sentido una suspensión temporal del Derecho resultaría finalmente imposible. El Estado asegura paradójicamente su continuidad al asumirse como katechon, es decir, al adoptar una "función de contención" ante la amenaza eterna de un Apocalipsis que se cierne sobre él. En este sentido, las nociones de instante y de excepción en Schmitt se encuentran inscriptas bajo la forma de una Repräsentation política y existencial. La crítica de Benjamin permite explicitar que el peligro que busca conjurar a toda costa Schmitt consiste en la posibilidad de una interrupción radical del tiempo histórico. Lejos de aceptar la posición schmittiana, el filósofo berlinés buscará poner en cuestión los supuestos en torno al tiempo y a la historia que hacen posible dicha concepción.

El tercer apartado fue dedicado a desplegar esta apuesta filosófico-política tal como podemos encontrarla en su máxima expresividad y radicalidad filosófica en las Tesis. El rechazo de la teleología como sentido unívoco implica abandonar la empatía con los vencedores en pos de las generaciones derrotadas. En base a los desarrollos realizados, podemos plantear ahora los alcances de la inversión benjaminana: la tradición de los oprimidos enseña que el estado de excepción es la regla. No se trata para Benjamin de volver a enlazar una ilusión de continuidad para asegurar la permanencia máxima de un nuevo orden sino de encender la chispa en un instante de peligro. En ese sentido, el wirkliche Ausnahmezustand implica la interrupción de la historia de los vencedores en tanto supuesta Historia Universal que se impone violentamente sobre las generaciones oprimidas. La crítica que Benjamin elabora con vistas a una reformulación no se restringe a un ámbito teórico sino que implica también una praxis. En este sentido, y para terminar, quisiéramos recuperar el potencial filosófico-político de la Tesis I. ¿No es acaso el ajedrez el juego de la soberanía por excelencia? Desde la perspectiva benjaminiana, lo que el materialismo histórico no puede olvidar es que su partida es eminentemente política. Ningún progreso como ley histórica, ningún mecanismo causal, podrán representar la tradición de los oprimidos. En lugar de este dispositivo, el autor realiza una apropiación del mesianismo judío 
y su concepción de la memoria con el fin de encontrar allí un desplazamiento fundamental para re-elaborar su filosofía política de la historia. La respuesta benjaminiana al problema de la representación se encuentra en el entramado y en la estructura de las Tesis "Sobre el concepto de historia". La dialektisches Bild resulta la categoría que responde a este problema a través de una fusión entre pasado y presente: su praxis construye un salto entre generaciones que rompe con la continuidad causalmente determinada. La noción cardinal de Jetztzeit no busca reconstituir ninguna continuidad al modo schmittiano del instante de una decisión que contiene. Se trata, para Benjamin, de hacer saltar el continuum de la historia y para ello ha sido necesario emprender una crítica radical del pensamiento político de Schmitt. En conclusión, la posición benjaminiana sobre la representación implica la reformulación de aquello que entendemos por imagen y por memoria, por trascendencia y por mesianismo, por tiempo y por historia.

\section{Bibliografía}

Abadi F., y Espinosa, L., "La noción de muerte en la estética temprana de Walter Benjamin”, en Ágora. papeles de filosofía 33 , 2, 2014, pp. 167-183.

Agamben, G., Il tempo che resta. Un commento alla "Lettera ai romani”, Torino, Bollati Borighieri, 2000.

-, Stato di eccezione. Homo sacer, II, 1, Torino, Bollati Boringhieri, 2003.

Benjamin, W., Gesammelte Schriften, Tiedemann, R. y Schweppenhäuser, H. (eds.), con la colaboración de Adorno Th. W. y Scholem G., Frankfurt a.M., Suhrkamp, 1991.

-, El origen del drama barroco alemán, trad. Muñoz Millanes, J., Madrid, Taurus, 1990.

-, Para una crítica de la violencia y otros ensayos, trad. Blatt, R., Madrid, Taurus, 2001.

-, Libro de los pasajes, trad. Fernández, L., Herrera I. y Guerrero, F., Madrid, Akal, 2007.

Bredekamp, H., "Der simulierte Benjamin: Mittelalterliche Bemerkungen zu seiner Aktualität", en Berndt, A. et al (eds.), Frankfurter Schule und Kunstgeschichte, Berlin, Reimer Verlag, 1992, pp. 117-140.

-, Thomas Hobbes: visuelle Strategien. Der Leviathan: Urbild des modernen Staates. Werkillustrationen und Portraits, Berlin, Akademie Verlag, 1999.

-, "From Walter Benjamin to Carl Schmitt, via Thomas Hobbes", en Critical Inquiry, 25, 2, trad. Thorson Hause M. y Bond, J., 1999, pp. 247-266.

Buck-Morss, S., The Dialectics of Seeing. Walter Benjamin and the Arcades Project, Cambridge, The MIT Press, 1989.

Catanzaro, G., "Justicia y Monadología: el roce entre el materialismo benjaminiano y la metafísica de Leibniz en la Crítica del Conocimiento”, en Anacronismo e Irrupción. Revista de Teoría y Filosofía Política Clásica y Moderna 2, 2, 2012, pp. 170204.

Conrad, B., "Kierkegaard's Moment. Carl Schmitt and His Rhetorical Concept of Decision”, en Palonen, K. (ed.), Redescriptions: Yearbook of Political Thought, Conceptual History and Feminist Theory, Berlin, Lit Verlag, 2011, pp. 145-171.

Damai, P., “The Killing Machine of Exception: Sovereignty, Law, and Play in Agamben's State of Exception”, en CR: The New Centennial Review 5, 3, 2005, pp. 255-276.

Dotti, J., “Teología política y excepción”, en Daimon. Revista de Filosofia 13, 1996, pp. 129-140.

-, "Ménage à trois sobre la decisión excepcional. Kierkegaard, Constant y Schmitt", en Deus Mortalis. Cuaderno de filosofía política 4, 2005, pp. 303-380.

Duso, G., "Carl Schmitt: teología política e lógica dei concetti politici moderni”, en Daimon. Revista de Filosofía 13, 1996, pp. 77-98.

-, La rappresentanza politica: genesi e crisi del concetto, Milano, Franco Angeli, 2003.

Dyzenhaus, D., (ed.), Law as Politics: Carl Schmitt's Critique of Liberalism, Durham, Duke University Press, 1998.

Ferejohn, J., y Pasquino, P., "The Law of the Exception: A Typology of Emergency Powers", en International Journal of Constitutional Law 2, 2004, pp. 210-239.

Fleisner, P., La vida que viene, Buenos Aires, EUDEBA, 2015.

Galindo Hervás, A., "Lo impolítico, la esquizofrenia. Variaciones sobre el mito", en ALFA 14, 2004, pp. 103-111, Versión electrónica en http://www.saavedrafajardo.org/archivos/trabajos/trab003-agh.pdf, consultado el 10/01/2017, pp. 1-9.

-, La soberanía. De la teología política al comunitarismo impolítico, Murcia, Res Publica, 2003.

-, “Mesianismo impolítico", en Isegoría 39, 2008, pp. 239-250.

-, Pensamiento impolítico contemporáneo. Ontología (y) política en Agamben, Badiou, Esposito y Nancy, Madrid, Sequitur, 2015.

Galli, C., Genealogia della politica, Bologna, Il Mulino, 1996.

-, Lo sguardo di Giano. Saggi su Carl Schmitt, Bologna, il Mulino, 2008.

Gómez Orfanel, G., Excepción y normalidad en el pensamiento de Carl Schmitt, Madrid, Centro de Estudios Constitucionales, 1986.

Grossheutschi, F., Carl Schmitt und die Lehre vom Katechon, Berlin, Duncker \& Humblot, 1996.

Heil, S., Gefährliche Beziehungen. Walter Benjamin und Carl Schmitt, Stuttgart, Metzler, 1996.

Hell, J., "Katechon: Carl Schmitt's Imperial Theology and the Ruins of the Future", en The Germanic Review 84, 4, 2009, pp. 283-326.

Hofmann, H., Legitimität gegen Legalität. Der Weg der politischen Philosophie Carl Schmitts, 2da ed., Berlin, Duncker \& Humblot, 1992. 
Kambas, C., "Walter Benjamin an Gottfried Salomon: Bericht über eine unveröffentlichte Korrespondenz", en Deutsche Vierteljahrsschrift für Literaturwissenschaft und Geistesgeschichte 56, 1982, pp. 601-621.

Kierkegaard, S., La repetición, trad. Gutiérrez Rivero, D., Madrid, Alianza, 2009.

Kuffer Dinerstein, P., “«Leer lo que nunca fue escrito»: hacia una hermenéutica política”, en Ágora. Papeles de Filosofia 34, 1, pp. 213-221.

Küpper, T., y Skrandies, T., "Rezeptionsgeschichte”, en Lindner, B. (ed.), Benjamin-Handbuch: Leben-Werk-Wirkung, Stuttgart, Metzler, 2006, pp. 17-56.

Löwy, M., Walter Benjamin: avertissement d'incendie, Paris, PUF, 2001. Versión en castellano: Walter Benjamin. Aviso de incendio, trad. Pons, H., Buenos Aires, FCE, 2002.

Mayorga Ruano, J., Revolución conservadora y conservación revolucionaria. Política y memoria en Walter Benjamin, Barcelona, Anthropos Editorial/UAM-Iztapalapa-México, 2003.

Meierhenrich, J., y Simons, O., (eds.) The Oxford Handbook of Carl Schmitt, Oxford, Oxford University Press, 2016.

Mehring, R., Carl Schmitt: Aufstieg und Fall. Eine Biographie, München, C.H. Beck, 2009.

-, “"Geist ist das Vermögen, Diktatur auszuüben» Carl Schmitts Marginalien zu Walter Benjamin”, en Weidner D. y Weigel, S., Benjamin-Studien 2, Fink Wilhelm, 2011, pp. 239-256.

-, Kriegstechniker des Begriffs. Biographische Studien zu Carl Schmitt, Tübingen, Mohr Siebeck, 2014.

-, Carl Schmitt: Denker im Widerstreit: Werk - Wirkung - Aktualität, Freiburg/München, Verlag Karl Alber, 2017.

Meuter, G., Der Katechon: Zu Carl Schmitts fundamentalistischer Kritik der Zeit, Berlin, Duncker \& Humblot, 1994.

Molano, M., "Walter Benjamin: historia, experiencia y modernidad", en Ideas y Valores 63, 154, 2014, pp. 165-190.

Mosès, S., L'Ange de l'histoire. Rosenzweig, Benjamin, Scholem, Paris, Seuil, 1992. Versión en castellano: El ángel de la historia. Rosenzweig, Benjamin, Scholem, trad. Martorell, A., Madrid, Cátedra, 1997.

Müller, J-W., "Myth, law and order: Schmitt and Benjamin read reflections on violence", en History of European Ideas 29, 2003, pp. 459-473.

Naishtat, F., ¿¿Hay una escatología barroca en el Trauerspielbuch? Agamben vs. Scholem”, en Actas de las IX Jornadas de Investigación en Filosofia de la FHCE de la UNLP, 2013, pp. 1-11.

Paléologue, T., Sous l'oeuil du grand inquisiteur: Carl Schmitt et l'heritage de la theologie politique, Paris, Editions du Cerf, 2004

Palzhoff, Th., y Treml, M., (eds.), Jacob Taubes and Carl Schmitt: Briefwechsel mit Materialien, München, Fink, 2012.

Pan, D., "Against Biopolitics: Walter Benjamin, Carl Schmitt, and Giorgio Agamben on Political Sovereignty and Symbolic Order", en The German Quarterly 82, 1, 2009, pp. 42-62.

Peisl, A., y Mohler, A. (eds.), Der Ernstfall (Schriften der “Carl Friedrich von Siemens-Stiftung” Bd. 2), Frankfurt a.M./Berlin/ Wien, Propyläen Verlag, 1979.

Polgovsky Ezcurra, M., “On «Shock»: The Artistic Imagination of Benjamin and Brecht”, en Contemporary Aesthetics 10, 2012, pp. 1-10.

Mate, R., Medianoche en la historia, Madrid, Trotta, 2006.

Rumpf, M., "Radikale Theologie: Walter Benjamins Beziehung zu Carl Schmitt", en Gebhardt, P. et al, Walter Benjamin Zeitgenosse der Moderne, Kronberg, Scriptor, 1976, pp. 37-50.

Sander, H.-D., Marxistische Ideologie und allgemeine Kunsttheorie, Tübingen, Mohr, 1975.

Scheuerman, W., Carl Schmitt: The End of Law, Lanham, Rowman \& Littlefield, 1999.

-, Carl Schmitt: The End of Law, Boston, Rowman \& Littlefield, 1999.

Schmitt, C., "Diktatur und Belagerungszustand", en Zeitschrift fur das gesamte Strafrechtswissenschaft 38, 1916, pp. 138-162.

-, "Die Einwirkungen des Kriegszustandes auf das ordentliche strafprozessuale Verfahren", Zeitschrift fur die gesamte Strafrechtswissenschaft 38, 1917, pp. 783-797.

-, "Die Sichtbarkeit der Kirche. Eine scholastische Erwägung", en Summa: Eine Vierteljahresschrift 2, 1917, pp. 71-80. Versión en castellano: "La visibilidad de la Iglesia. Una reflexión escolástica", trad. García, R., en Daimon. Revista de filosofía 13, 1996, pp. 11-18.

-, Die Diktatur, München, Duncker \& Humblot, 1921. Versión en castellano: La dictadura, trad. Díaz García, J., Madrid, Alianza Editorial, 1985.

-, Politische Theologie. Vier Kapitel zur Lehre von der Souveränität. Berlin, Duncker \& Humblot, 1979. Versión en castellano: Teología política. Cuatro capítulos sobre la doctrina de la soberanía, en Teología política, trad. Conde F. J. y Navarro Pérez, J., epílogo de Villacañas, J. L., Madrid, Trotta, 2009.

-, Römischer Katholizismus und politische Form, Stuttgart, Klett-Cotta, 1984.

-, Über die drei Arten des rechtswissenschaftichen Denkens, Hamburg, Hanseatische Verlagsanstalt, 1934.

-, Land und Meer: Eine weltgeschichtliche Betrachtung, Leipzig, Reclam Verlag, 1942.

-, Der Nomos der Erde im Völkerrecht des “Jus Publicum Europaeum”, Köln, Greven Verlag, 1950. Versión en castellano: El Nomos de la Tierra en el Derecho de Gentes del "Jus Publicum Europaeum”, trad. D. Schilling, Buenos Aires, Ed. Struhart \& Cía, 2005.

-, "Drei Stufen historischer Sinngebung” ["Drei Möglichkeiten eines christlichen Geschichtsbildes"], Universitas 5:8, 1950, pp. 927-931. Versión en castellano: “Tres posibilidades de una visión cristiana de la Historia”, en Arbor 62.II, 1951, pp. 237241.

-, Hamlet oder Hekuba. Der Einbruch der Zeit in das Spiel, Düsseldorf, E. Diederichs, 1956. Versión en italiano: Amleto o Ecuba: L'irrompere del tempo nel gioco del dramma, trad. Forti, S., Bologna, Il Mulino, 1983. Versión en castellano: Hamlet o Hécuba. La irrupción del tiempo en el drama, trad. García, Valencia, R., Pre-Textos/Universidad de Murcia, 1994.

Schmitz, M., Die Freund-Feind-Theorie Carl Schmitts. Entwurf und Entfaltung, Köln-Opladen, Westdeutscher Verlag, 1965.

Schwab, G., The Challenge of the Exception: An Introduction to the Political Ideas of Carl Schmitt between 1921 and 1936, 2da ed., New York, Greenwood, 1989.

Taubes, J., Ad Carl Schmitt. Gegenstrebige Fügung, Berlin, Merve, 1987. 
-, Die politisches Theologie des Paulus, München, Wilhelm Fink, 1993. Versión en castellano: La teología política de Pablo, trad. García-Baró, M., Madrid, Trotta, 2007.

Thaler, J., “Genial. Carl Schmitt liest Walter Benjamin”, en Atze M. y Kaukoreit V. (eds.), Lesespuren-Spurenlesen oder Wie kommt die Handschrift ins Buch? Von sprechenden und stummen Annotationen, vols. 12/13, Wien, Praesens, 2013, pp. $246-251$.

Tielke, M., "Die Bibliothek Carl Schmitts", en Schmittiana N. F. Bd. I, 2011, pp. 257-332.

Uslenghi, A. (comp.), Walter Benjamin: Culturas de la imagen, trad. Villegas, S., Buenos Aires, Eterna Cadencia Editora, 2010.

Van Laak, D., y Villinger, I., Nachlass Carl Schmitt: Verzeichnis des Bestandes im nordrhein-westfälischen Hauptstaatsarchiv (Veröffentlichungen der Staatlichen Archive NRW - Reihe C), Siegburg, Respublica-Verlag, 1993.

Viesel, H., Jawohl, der Schmitt: Zehn Briefe aus Plettenberg, Berlin, Support Edition, 1988.

Villacañas, J. L., y García, R., "Walter Benjamin y Carl Schmitt: Soberanía y estado de excepción", en Daimon. Revista de filosofia 13, 1996, pp. 41-60.

Weber, S., "Taking Exception to Decision: Walter Benjamin and Carl Schmitt", en Diacritics: a review of contemporary criticism 22, 3/4, 1992, pp. 5-18. 